\title{
LOUISA JACKSON
}

\section{ACQUIRED BRAIN INJURY AND SERIOUS CRIMINAL OFFENDERS: AN ARGUMENT TO EXPAND THE COURT'S THERAPEUTIC JURISDICTION}

\section{LLB (HONS) RESEARCH PAPER \\ LAWS513: LAW AND MEDICINE}

\section{FACULTY OF LAW}

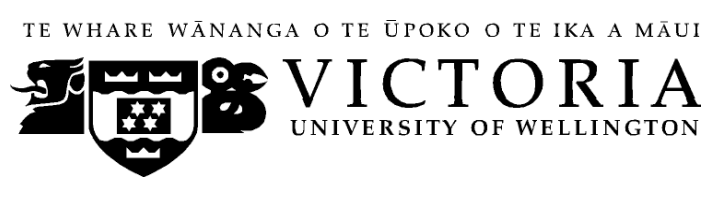

2013 


\section{Contents}

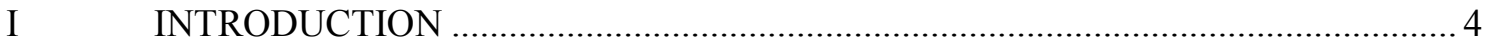

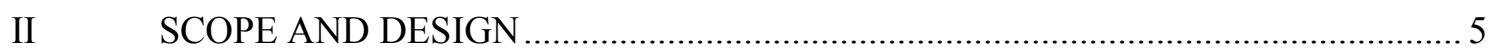

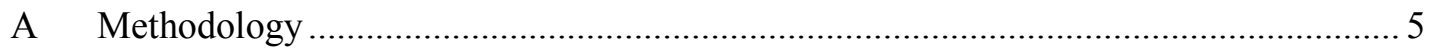

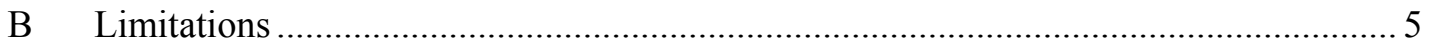

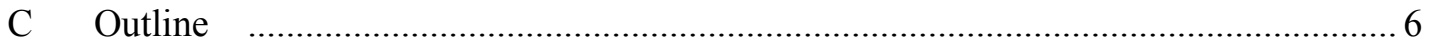

III ACQUIRED BRAIN INJURY AND CRIMINAL OFFENDING ............................ 6

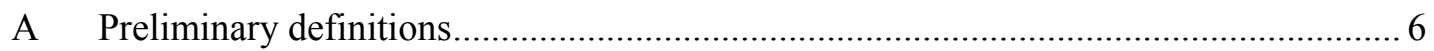

B Executive dysfunction: the consequences of ABI............................................... 7

C ABI, executive dysfunction, and criminality ......................................................... 8

1 The etiology of serious criminality in people with ABI .............................. 9

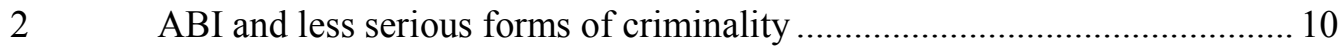

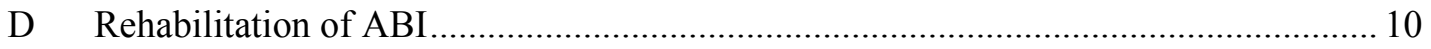

IV THE CRIMINAL JUSTICE SYSTEM AND MENTALLY IMPAIRED

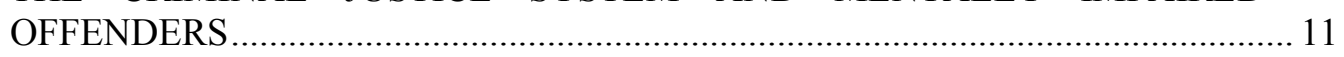

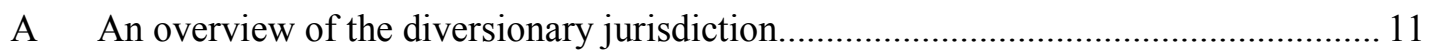

B The theoretical basis for therapeutic diversion from prison........................................ 12

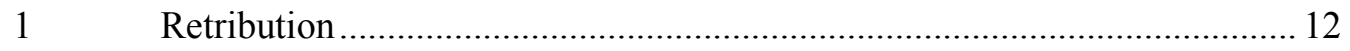

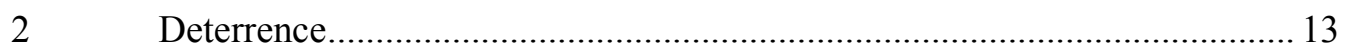

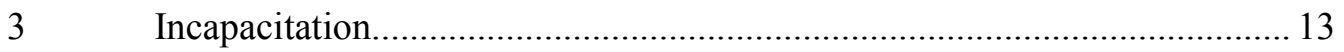

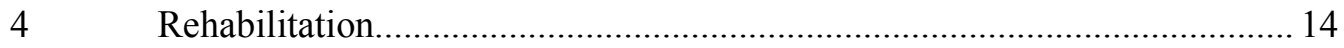

V PATHWAYS TO TREATMENT: THERAPEUTIC DISPOSITIONS ….................. 15

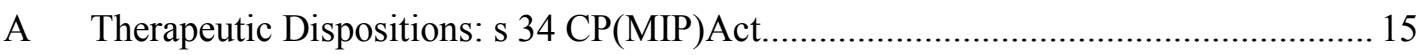

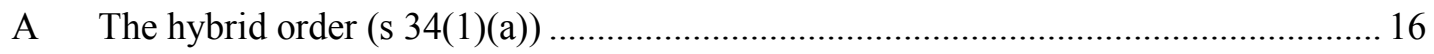

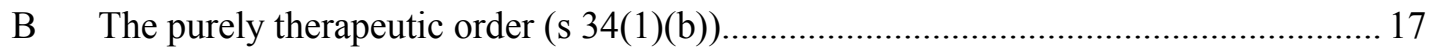

C Treatment and punishment: theoretical contradictions in the s 34 orders.................... 18

VI PARAMETERS ON THERAPEUTIC DISPOSITIONS: "INTELLECTUAL

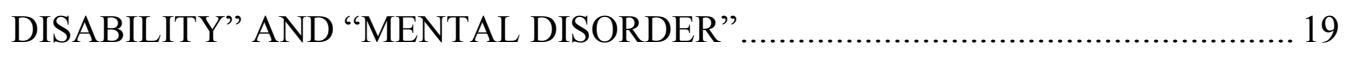

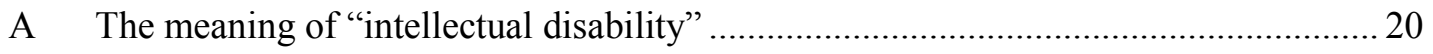

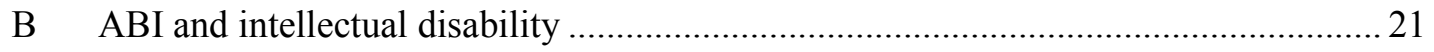

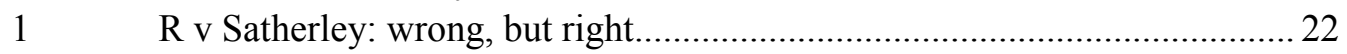

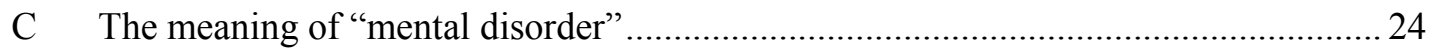

1 The definition of "mental disorder" and its consequences .......................... 24

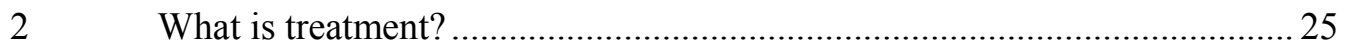

3 Interpreting "mental disorder" with a "treatability" requirement ................. 26

$4 \quad$ Why treatability should be a component of mental disorder and not the

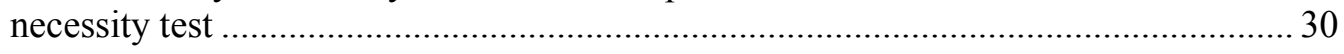

$5 \quad$ How a treatability requirement may impact the civil jurisdiction ................ 31

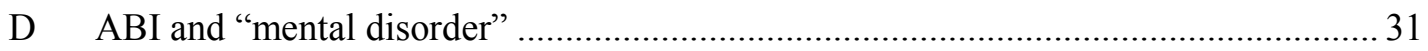

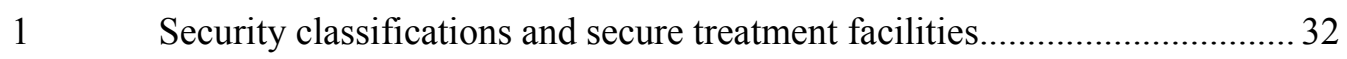

2 How ABI is untreatable under the MH(CAT)Act ..................................... 33

$3 \quad$ Blackwood v R: an illustration of the problem........................................... 34

$4 \quad \mathrm{ABI}$ as a mental disorder for the purpose of civil commitment..................... 37

VII IMPRISONING ABI OFFENDERS: WHY THE THERAPEUTIC

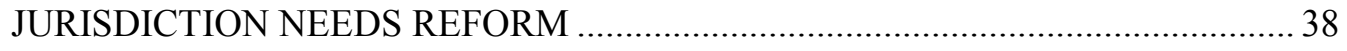




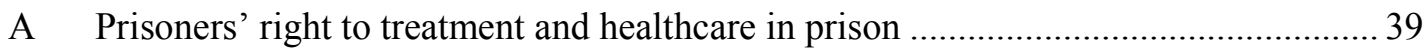

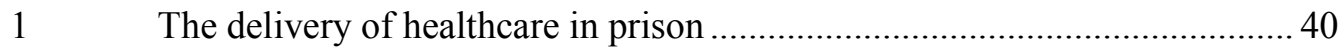

$2 \quad$ ABI rehabilitation in prison: a breach of the right to treatment.................... 41

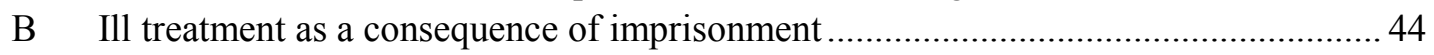

$1 \quad$ The right to be free from ill treatment .....................................................4 44

2 Does imprisoning an offender with ABI amount to ill treatment? ............... 46

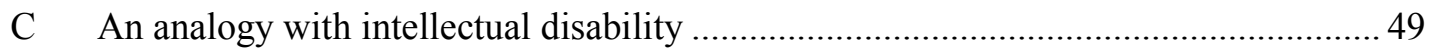

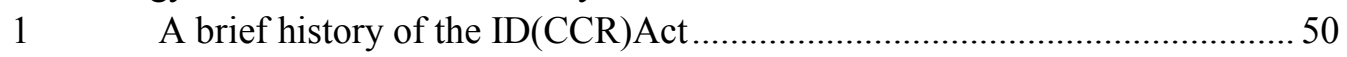

2 A similar path: what the ID(CCR)Act's history shows about ABI

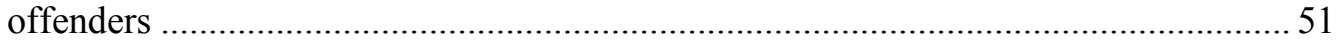

VIII ADDRESSING THE INEQUITY: HOW TO BETTER PROVIDE FOR ABI

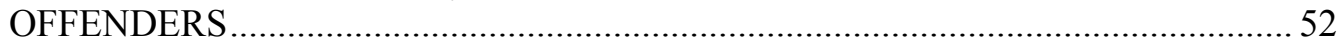

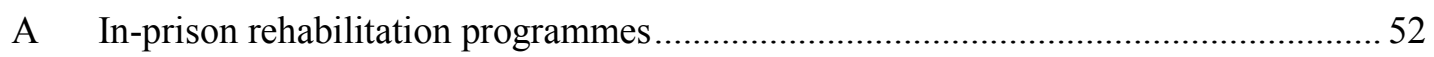

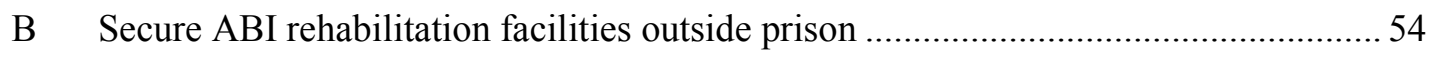

1 Expanding the mental disorder definition under the MH(CAT)Act.............55

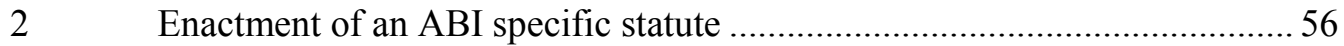

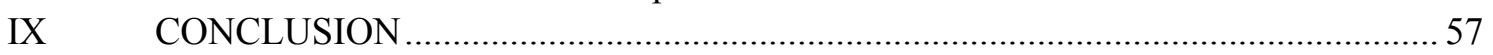

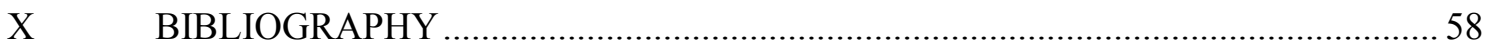

Word count

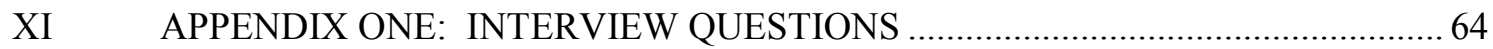

XII APPENDIX TWO: OFFENDERS WITH MENTAL IMPAIRMENT LEGISLATIVE PATHWAYS TO TREATMENT OR PUNISHMENT .....................6 65 


\section{Introduction}

Brain injury is a debilitating mental impairment. It can cause aggression, impulsivity, and other socially challenging behaviours, including criminal offending. ${ }^{1}$ This is largely a consequence of damage to the frontal lobes, the part of the brain that facilitates selfregulation and emotional control. Remedying this requires specialist rehabilitation, preferably in dedicated facilities. $^{2}$ However, rather than being in such facilities, a disproportionate number of brain injured New Zealanders are in prison, often for violent or sexual offences. ${ }^{3}$ By contrast, other mentally impaired offenders, such as the intellectually disabled and mentally ill, are not kept in prison but instead transferred to the health jurisdiction to receive treatment or care. This raises a question as to why brain injured offenders do not receive the same therapeutic response by our criminal justice system.

This paper explores that question by examining the current legislative framework for diverting mentally impaired offenders into healthcare through therapeutic dispositions on sentencing. It demonstrates the inadequacy of this framework for violent or sexual offenders with brain injury by showing how the gateway definitions of "intellectual disability" and "mental disorder" exclude that condition. It then explores the appropriateness of imprisoning serious offenders with brain injury by examining whether their detention breaches the state's statutory obligations, and argues that the status quo violates both the Corrections Act 2004 and the New Zealand Bill of Rights Act 1990. Finally, in recognition of the current exclusion of brain injured offenders from therapeutic dispositions, and the potential illegality of their detention in prison, this paper argues for an expansion of the court's therapeutic jurisdiction and examines mechanisms to achieve this.

$1 \quad$ Judith Aharon-Peretz and Rachel Tomer "Traumatic Brain Injury" in Bruce Miller and Jeffrey Cummings (eds) The Human Frontal Lobes: Functions and Disorders (2nd ed, The Guilford Press, New York, 2007) at 541 and 544; Max Cavit and Allison Foster "Traumatic Brain Injuries among Corrections Populations: Implications and Intervention Strategies” (2010) Rethinking Crime and Punishment $<$ www.rethinking.org.nz $>$.

2 Interview with Allison Foster PhD, Research Director, ABI Rehabilitation (the author, 27 June 2013); Interview with Wol Hansen, Counsellor and Psychologist (registration pending) (the author, 26 June 2013).

3 National Health Committee Health in Justice: Kia Piki te Ora, Kia Tika! Improving the Health of Prisoners and their Families and Whanau (Ministry of Health, 2010) at 3 and 92; Tracey Barnfield and Janet Leathem "Incidence and outcomes of traumatic brain injury and substance abuse in a New Zealand prison population" (1998) 12 Brain Injury 455. 


\section{Scope and Design}

\section{A Methodology}

The information used for this analysis was obtained from two main sources. Primary research was undertaken with three health practitioners with relevant qualifications or experience working with brain injured offenders. Ethics approval was obtained for this research. The practitioners were interviewed with a set of standardised questions about brain injury, its link to criminal offending, and the appropriateness of treatment in various facilities. ${ }^{4}$ The practitioners were each provided a copy, and approved, the interview notes taken. The information obtained was then used to inform the author's analysis of the appropriateness of the current regime and is cited where appropriate. Secondary research was also undertaken. A brief literature review of scientific material on brain injury and its connection to criminal offending was carried out. Second, a review of statute and case law on the current therapeutic jurisdiction was undertaken, including supporting academic commentary. This material was used to describe the current regime and is also cited where appropriate and listed in the bibliography.

\section{B Limitations}

This paper is limited in scope in three ways. First, it only focuses on brain injured offenders who commit serious imprisonable offences, such as sexual or violent crimes, for whom community sentences are not possible. It is acknowledged that a problem also exists in respect of brain injured offenders who commit non-imprisonable offences, for whom no diversionary mechanism exists at all. It is also acknowledged that the legal position may vary for brain injured offenders who commit offences that do not require imprisonment, as different sentencing options are available to the courts in that situation. However, this paper will not examine those two categories.

Second, this paper only discusses the legal framework for post-conviction dispositions. It excludes consideration of pre-conviction mechanisms, such as fitness to plead and insanity. It also excludes analysis of a much broader and related legal policy issue as to how the criminal justice system (including the police, lawyers, and courts) identify and respond to brain injured (and other cognitively impaired) persons at the point of first

The set of questions used for these interviews is annexed as Appendix One. 
engagement and the type of supports and protections they receive during police questioning, criminal investigation, and trial.

Finally, the paper also excludes consideration of mental impairment as a mitigating factor in sentencing. For completeness, it is noted that a court can reduce the length or severity of an offender's sentence through recognising a mental impairment as causing "diminished intellectual capacity", 5 or the conditions of prison as being unduly severe because of the impairment. ${ }^{6}$ However, despite the mitigation power being obviously related to the topic, this paper lacks the scope to consider how it is used to ameliorate punitive sentences for the mentally impaired and limits itself to therapeutic dispositions only.

\section{Outline}

By way of overview, this paper is constructed as follows. First, in Part III, a brief survey of the literature on brain injury and its connection to increased criminal behaviour is provided. Part IV then introduces the rationales behind the current mental impairment framework and the theories as to why mentally impaired offenders are not appropriate subjects for orthodox criminal punishment. In Part $\mathrm{V}$ the legislative mechanisms for diversion of mentally impaired offenders into healthcare are explained. Part VI demonstrates how the threshold definitions for such diversion exclude brain injury. Part VII then explores how imprisoning brain injured offenders may violate prisoners' rights to demonstrate why the continued exclusion of such offenders from the court's therapeutic jurisdiction is untenable. Finally, Part VIII discusses options for reform.

\section{Acquired Brain Injury and Criminal Offending}

\section{A Preliminary definitions}

The literature on brain injury employs a number of closely related and overlapping terms, differentiated here for clarity. First, "acquired brain injury" (ABI) is used to describe any brain injury experienced after birth. ${ }^{7}$ Such an injury may result from hypoxia, infection, stroke, or physical trauma. As such, ABI encompasses the related term "traumatic brain injury" (TBI) which refers to a brain injury resulting from an external application of force

\footnotetext{
$5 \quad$ Sentencing Act 2002, s 9(2)(e).

$6 \quad$ Ibid, s $8(\mathrm{~h})$.

7 ABI Rehabilitation "Brain Injury Information" < www.abi-rehab.co.nz>.
} 
to the head as occurs in a car accident, fall, or assault. ${ }^{8}$ An associated term is "head injury". This describes the originating injury leading to a TBI. ${ }^{9}$ However, head injury does not necessarily result in brain injury, and brain injury can occur without head injury, so the two terms are not synonymous (although sometimes used as such). ${ }^{10}$ In this paper, the umbrella term ABI is used unless a more specific term is used in a source document. However, it is noted that most brain injured offenders have traumatic, rather than nontraumatic, injuries, largely from car accidents or assault. ${ }^{11}$

\section{$B$ Executive dysfunction: the consequences of $A B I$}

A nexus between ABI and adverse social behaviour is well recognised. ${ }^{12}$ While every person with $\mathrm{ABI}$ has a unique set of symptoms, common post-injury experiences include increased fatigue and irritability, ${ }^{13}$ cognitive deficits (difficulties in informationprocessing, memory, and attention) and difficulties with behavioural control (including impulsivity, aggression, and obsessive compulsive behaviour). ${ }^{14}$ These issues result from physical damage to the frontal cortex, the part of the brain that facilitates self-regulation (the ability to stop oneself before saying or doing something inappropriate), higher reasoning (the ability to use memory to foresee consequences), and socio-adaptive capacities such as empathy (the ability to identify and understand the feelings of other people). ${ }^{15}$

This pattern of behaviour following ABI is termed "executive dysfunction". ${ }^{16}$ The behavioural effects of executive dysfunction can be severe: studies have demonstrated

\footnotetext{
Cavit and Foster, above $\mathrm{n} 1$.

9 New Zealand Guidelines Group Traumatic Brain Injury: Diagnosis, Acute Management and Rehabilitation: Summary (Accident Compensation Corporation, 2007) at 1.

10 Ibid.

11 Barnfield and Leathem, above n 3, at 461.

12 Aharon-Peretz and Tomer, above n 1, at 541 and 544.

13 Cavit and Foster, above $\mathrm{n} 1$.

14 Aharon-Peretz and Tomer, above n 1, at 541 and 544; Cavit and Foster, above n 1; Elisa Lavelle and Suzanne Barker-Collo "Neuropsychology and the Assessment of Competence" in Fred Seymour, Suzanne Blackwell and John Thorburn (eds) Psychology and the Law in Aotearoa New Zealand (New Zealand Psychological Society, Wellington, 2011) at 220.

15 W Williams and others "Traumatic Brain Injury in a Prison Population: Prevalence and Risk for ReOffending" (2010) 24 Brain Injury 1184; Lavelle and Barker-Collo, above n 14, at 220-221; Interview with Foster, above $\mathrm{n} 2$.

16 Lavelle and Barker-Collo, above $\mathrm{n} \mathrm{14}$, at 221. It is also sometimes referred to as "frontal lobe disorder" but this paper will use the term "executive dysfunction".
} 
damage to the frontal cortex causing a marked increase in a person's propensity to physical or verbal violence, ${ }^{17}$ long-term issues with poor judgement and decisionmaking, ${ }^{18}$ and an increased likelihood of comorbid mental illness or psychosis. ${ }^{19}$ Executive dysfunction can also be very long-lasting: in one study of brain injured persons, more than $50 \%$ of participants demonstrated personality changes and emotional difficulties up to 15 years after the original head injury. ${ }^{20}$ As such, it is now widely accepted that ABI causes considerable adverse effects on cognitive functioning and behaviour. As such, ABI-related executive dysfunction can be categorised as a mental impairment of equivalent severity to intellectual disability or mental illness.

\section{ABI, executive dysfunction, and criminality}

$\mathrm{ABI}$ is also connected to criminal offending. Two quantitative studies undertaken in New Zealand demonstrate this relationship. First, a 1998 study found $78.8 \%$ of a Whanganui prison population had experienced a TBI of some seriousness, with $10.8 \%$ demonstrating severe TBI. ${ }^{21}$ Supporting this, a 2005 New Zealand Prisoner Health Survey identified $64 \%$ of prisoners had experienced a head injury during their lifetime (although, as noted, this does not necessarily mean all 64\% would have had an ABI). ${ }^{22}$ By contrast, the rate of $\mathrm{ABI}$ in the general population is considerably lower. As compared with the $78 \%$ of Whanganui prison inmates who had experienced TBI during their lifetime, only about $2 \%$ of the general population in New Zealand have experienced TBI. ${ }^{23}$ Such a considerable disjunct in the prevalence rates of ABI between offending and non-offending populations indicates a relationship between ABI and criminal offending in New Zealand.

The domestic research findings are consistent with research undertaken in comparable jurisdictions. In the United Kingdom, research showed $60.7 \%$ of a local prison population had a history of head injury, with $16 \%$ of that population demonstrating

$17 \quad$ Jose Leon-Carrion and Francisco Javier Chacartegui Ramos "Blows to the head during development can predispose to violent criminal behaviour: rehabilitation of consequences of head injury is a measure for crime prevention" (2003) 17 Brain Injury 207 at 208.

18 Aharon-Peretz and Tomer, above n 1, at 545.

19 New Zealand Guidelines Group Traumatic Brain Injury: Diagnosis, Acute Management and Rehabilitation (Accident Compensation Corporation, 2006) at 173 and 174.

20 Aharon-Peretz and Tomer, above n 1, at 544.

$21 \quad$ Barnfield and Leathem, above n 3, at 459.

22 National Health Committee, above n 3, at 3 and 92.

23 Cavit and Foster, above $\mathrm{n}$ 1. It is acknowledged that many people experiencing mild TBI may not seek medical attention and as such, the rate of $\mathrm{ABI}$ in both populations may be higher. 
moderate to severe TBI. ${ }^{24}$ Similarly, in Australia, corrections' data identified $42 \%$ of male inmates and $33 \%$ of female had cognitive impairment, including ABI. ${ }^{25}$ As such, there seems to be an internationally established correlation between ABI and offending, broadly equivalent to that found in New Zealand. The exact nature of the relationship between ABI and offending is less certain, as discussed below.

\section{The etiology of serious criminality in people with ABI}

Despite the obvious statistical correlation, the etiology of criminality in the ABI population is not entirely clear. Not all people with ABI commit criminal offences and, as such, there is no absolute or determinative relationship between the two. ${ }^{26}$ Rather, practitioners characterise the relationship as correlative, with the effects of ABI seen to "trigger" certain behaviours that may then lead to criminal offending. ${ }^{27}$

This view of $\mathrm{ABI}$ as correlated to, not causative of, offending is supported by international literature. ${ }^{28}$ The theory can be summarised as follows. Executive dysfunction means a person with ABI experiences difficulty in mediating and controlling their behaviour. ${ }^{29}$ When faced with a confrontational or stressful situation (such as a domestic dispute) a person with $\mathrm{ABI}$ is much more likely to respond with physical aggression or violence than a person without $\mathrm{ABI}$, whose brain has a greater capacity to utilise non-violent socio-adaptive skills such as negotiation or dialogue to respond to the situation. $^{30}$

This cognitive or functional deficit is compounded by increased levels of fatigue, irritability, or frustration experienced as a consequence of $\mathrm{ABI}$, independently working to lower a person's "flash point" for aggression. ${ }^{31}$ Consequently, people with ABI have a heightened propensity to commit acts of violence, and therefore to commit criminal acts,

\footnotetext{
W Williams and others, above n 15, at 1186.

25 Parliament of Victoria Law Reform Committee Inquiry into Access to and Interaction with the Justice System by People with an Intellectual Disability and their Families and Carers - Final Report (Parliamentary Paper 216, 2013) at xxii.

26 Interview with Foster, above n 2; Interview with Hansen, above $\mathrm{n} 2$.

27 Ibid.

28 Drew Barzman and Manish Fozdar “Does traumatic brain injury cause violence?” (2002) 1 Journal of Family Practice; Leon-Carrion and Ramos, above n 17; W Williams and others, above n 15.

29 Leon-Carrion and Ramos, above n 17, at 213.

$30 \quad$ Ibid.

31 Interview with Foster, above n 2; Interview with Hansen, above n 2.
} 
than people without ABI. This relationship is particularly pronounced when the person has other biological or social risk factors predisposing them to offending such as social environment, substance abuse, employment status, ethnicity, or gender. ${ }^{32}$

People with ABI also have a heightened propensity to commit sexual offences. People with ABI experience disinhibition, causing them to act impulsively and without processing risk and consequence (including the effects of their behaviour on others). ${ }^{33}$ Disinhibition can lead to hypersexuality and sexually inappropriate behaviour, ${ }^{34}$ manifesting as inappropriate touching, sexual aggression, or even rape. ${ }^{35}$ Such behaviour is obviously criminal. Thus, ABI-related executive dysfunction can predispose persons to serious violent or sexual criminal behaviour through reducing their capacity to utilise 'rational' responses to confrontation, stress, or sexual impulses.

\section{ABI and less serious forms of criminality}

While outside the scope of this paper, it should be noted that non-violent forms of criminality are also linked to ABI. People with ABI can be predisposed to commit low level judgement-related offences such as speeding, driving without a licence, or stealing. ${ }^{36}$ Propensity for such offending is also seen to result from ABI-related cognitive deficits and, in particular, the reduced capacity to foresee consequence and process risk (poor decision-making). ${ }^{37}$ When combined with impulsivity or a social environment that facilitates criminality, the likelihood of this non-violent offending is most pronounced. A robust legal framework for managing brain injured offenders must also provide for such lower level offending, but consideration of this falls outside this paper.

\section{Rehabilitation of $A B I$}

The adverse cognitive and behavioural effects of ABI are not necessarily permanent. Internationally, ABI rehabilitation is statistically correlated to lower levels of aggression

\footnotetext{
Leon-Carrion and Ramos, above n 17, at 209.

Aharon-Peretz and Tomer, above n 1, at 545.

New Zealand Guidelines Group, above n 19, at 114.

Ibid.

See, for example, Ministry of Health v M FC Manukau FAM-2006-092-2802, 21 December 2006 where the brain injured person attempted to interfere with motor vehicles and Re DG [2003] NZFLR 87 (MHRT) where the brain injured person consistently drove without a licence.

37 See Lavelle and Barker-Collo, above n 14, at 220.
} 
and violence, ${ }^{38}$ and to reduced recidivism. ${ }^{39}$ As such, there is significant rehabilitation potential for $\mathrm{ABI}$ offenders. This is greatest where provided by ABI specialists in dedicated facilities. ${ }^{40}$ ABI is complex and has many "silent" symptoms (such as impulsivity) that risk going undetected where treatment is provided by general mental health practitioners. ${ }^{41}$ Of particular salience is that these symptoms are also the most linked to criminal offending. ${ }^{42}$ Accordingly, for treatment to be effective, specialist intervention is essential.

\section{The Criminal Justice System and Mentally Impaired Offenders}

The scientific literature discussed above shows ABI is a form of mental impairment. New Zealand's criminal justice system responds to most mentally impaired offenders by diverting them into the health jurisdiction to ensure their treatment, rehabilitation or care. This section of the paper outlines the theory behind, and options for, such therapeutic diversion.

\section{A An overview of the diversionary jurisdiction}

It is a well settled principle that mentally impaired persons should be treated differently to others in the criminal justice process. ${ }^{43}$ This stems from recognition that such persons have reduced mental capacity and rationality and are therefore less culpable for offending, less able to understand any punishment imposed, and may not be competent to participate in a traditional criminal trial. ${ }^{44}$ As such, diversion from the criminal justice system is accepted as appropriate. ${ }^{45}$

\footnotetext{
$38 \quad$ Leon-Carrion and Ramos, above n 17, at 214.

39 Cavit and Foster, above $\mathrm{n} 1$.

$40 \quad$ Interview with Foster, above $\mathrm{n} 2$.

41 Ibid.

$42 \quad$ Ibid.

43 Andrew Ashworth Sentencing and Criminal Justice (5th ed, Cambridge University Press, Cambridge, 2010) at 403.

44 Warren Brookbanks "The Sentencing and Disposition of Mentally Disordered Offenders" in Warren Brookbanks and Sandy Simpson (eds) Psychiatry and the Law (LexisNexis, Wellington, 2007) 197 at 199 and 206.

45 The sentencing of mentally impaired offenders is a complex area and it is acknowledged that at times an offender's mental impairment may actually result in an increase in a sentence's punitiveness, including preventive detention: $R v$ McGee (1995) 13 CRNZ 108 (CA). However, as this paper's primary focus is on the availability and use of therapeutic dispositions, it lacks scope to engage in a complete discussion of sentencing law in this area.
} 
Diversion can take several forms at different points in the criminal justice process, as illustrated in a flowchart annexed as Appendix Two. ${ }^{46}$ First, the person can be diverted from trial through being found unfit to plead, ${ }^{47}$ or diverted from conviction through the defence of insanity. ${ }^{48}$ Both of these pre-conviction mechanisms can be used for any mentally impaired person, including those whose impairment is ABI-related. ${ }^{49}$ However, fitness to plead and insanity both have high threshold conditions that are difficult to satisfy, and the perceived onerousness of the resulting disposition means these mechanisms are not widely used. ${ }^{50}$ Alternatively, and more commonly, mentally impaired people are tried and convicted for their offending, but diverted from prison through therapeutic dispositions on sentencing. ${ }^{51}$ These dispositions are the focus of this paper. The rationales for diverting the mentally impaired into healthcare are discussed below.

\section{B The theoretical basis for therapeutic diversion from prison}

While imprisonment is usually an appropriate sentence for people who have committed serious or violent offences, it is not so for mentally impaired offenders. This is because two of its primary rationales, retribution and deterrence, are rendered futile by the person's impairment, ${ }^{52}$ and the impairment makes rehabilitation a key sentencing goal.

\section{Retribution}

Retribution is a fundamental sentencing principle. It reflects the idea that the offender who has done something wrong or harmful deserves punishment. ${ }^{53}$ Punishment also communicates social and institutional disapproval of the behaviour and forces the offender to consider this, in the expectation it will promote remorse, accountability, and

\footnotetext{
The flowchart is the work of the author's and any error is accordingly hers.

47 Criminal Procedure (Mentally Impaired Persons) Act 2003, ss 7-19.

48 Ibid, ss 20-22.

49 See, for example, $\operatorname{Re} C$ MHRT08/057, 26 May 2008 which involved a person with ABI who was acquitted of sexual violation on account of insanity and Waitemata District Health Board v B (2005) 25 FRNZ 709 (DC) which involved a person with ABI who was found unfit to plead to a charge of sexual violation.

$50 \quad$ Ashworth, above n 43, at 403.

51 Brookbanks, above n 44, at 199.

$52 \quad$ Ibid, at 206.

53 Sir Bruce Robertson Adams on Criminal Law - Sentencing (online looseleaf ed, Brookers) at [SA7.01].
} 
ultimately lead to changed behaviour. ${ }^{54}$ However, a mentally impaired person may experience unique difficulty controlling antisocial behaviour, meaning punishment is less deserved. ${ }^{55}$ Equally, the mental impairment may mean the offender lacks the necessary cognitive capacity to understand the communicative element of punishment or respond to it. ${ }^{56}$ As such, the rationale of retribution is not well served by imprisoning mentally impaired offenders.

This is apposite to ABI offenders. Executive dysfunction renders ABI offenders less able to control impulses and so less blameworthy than non-impaired offenders for their behaviour. As such, they are less "deserving" of punishment than a fully rational criminal offender. Equally, an ABI offender, as a consequence of diminished cognitive capacity, is less able to understand and process the social communication of punishment and less able to autonomously reform their offending behaviour in response to it.

\section{Deterrence}

Deterrence is another fundamental rationale of imprisonment. Like retribution, it is also compromised when imprisoning the mentally impaired. Deterrence reflects the idea that when an offender is punished, such punishment (through its unpleasantness) will discourage further offending. ${ }^{57}$ This relies on an offender rationally processing risk and consequence before the offending behaviour is performed. Where a person is mentally impaired, such a rational response to the risk of punishment is unavailable. ${ }^{58}$ Diminished cognitive capacity, such as occurs with ABI, inhibits the processing of risk and consequence when making decisions. In addition, impulsivity or deficits in the ability to control one's behaviour when stressed, excited, or confronted, means a rational assessment of the prospect of punishment, even if cognitively possible, is unlikely to affect behaviour.

\section{Incapacitation}

As a consequence of the futility of deterrence and retribution, imprisonment of the mentally impaired becomes largely or solely based on the rationale of incapacitation,

Ashworth, above n 43, at 90.

Brookbanks, above n 44, at 206.

Ashworth, above n 43, at 403.

Robertson, above n 53, at [SA7.05].

Brookbanks, above n 44, at 206. 
detention to protect the public. ${ }^{59}$ In some situations this may be justified as mentally impaired offenders can pose a significant risk of danger to others, particularly when their impairment results in an inability to control violent behaviour. ${ }^{60}$ However, without such detention also involving the provision of treatment or rehabilitation, it risks being inhumane and violating human rights. ${ }^{61}$ As such, of itself, incapacitation is not an appropriate rationale for imprisoning mentally impaired offenders and could be challenged as a breach of the state's obligations.

\section{Rehabilitation}

Because the main rationales of imprisonment are not met by imprisoning mentally impaired offenders, and their impairment raises health and welfare needs, diversion is appropriate. Thus, the appropriate sentencing principle in such cases is rehabilitation. ${ }^{62}$ When sentencing for rehabilitative purposes, the court focuses on the welfare needs of the offender, rather than the gravity of their offence, and imposes a sentence that ensures such needs are met through an order requiring care or treatment. ${ }^{63}$

Rehabilitative sentences are not uncontroversial. As the conditions for release become connected with the "cure" of the offender's problem, there is a risk that a rehabilitative disposition may become disproportionate to the index offence. ${ }^{64}$ Consequently, impaired offenders risk being detained for treatment for a significantly longer period than would have been the case if detained for retribution. ${ }^{65}$ This compromises proportionality, a principle requiring the onerousness of a punishment to match the seriousness of the crime committed. ${ }^{66}$

However, where a mentally impaired offender would benefit from treatment or care, imprisonment would not serve any purpose other than incapacitation, and security

$59 \quad$ Robertson, above $\mathrm{n}$ 53, at [SA7.06].

60 Brookbanks, above n 44, at 199 and 212-213.

61 National Health Committee, above n 3, at [7.4.1]; Brookbanks, above n 44, at 214.

62 Ashworth, above $\mathrm{n}$ 43, at 404. This is not universally accepted. In some cases the court may identify the offender's impairment as creating a considerable risk of harm through the potential for recidivism. In this situation the court may use the mental impairment to justify the imposition of an extremely punitive sentence of preventive detention, rather than a therapeutic order: Brookbanks, above $\mathrm{n} 44$, at 209.

63 Ashworth, above n 43, at 86.

64 Ibid, at 87.

65 Brookbanks, above n 44, at 203.

66 Ibid, at 204. 
concerns can be addressed, a sentencing court should treat the offender's health needs as its primary concern. As authoritatively determined by the influential Mason Report, ${ }^{67}$ mentally impaired offenders should be the primary responsibility of the health system, not the corrections system. ${ }^{68}$ Not only is this more consistent with the state's obligations (examined in Part VII) but it is a better risk reduction strategy. Where mental impairment is connected to offending behaviour (whether directly or indirectly), addressing that impairment is more likely to reduce recidivism than punishment alone.

\section{$V$ Pathways to Treatment: Therapeutic Dispositions}

The preceding section of the paper identified why imprisoning mentally impaired offenders is inappropriate and diversion into therapeutic services preferred. This part discusses the legislative framework that facilitates therapeutic diversion, contained in the Criminal Procedure (Mentally Impaired Persons) Act 2003 ("CP(MIP)Act"), the Mental Health (Compulsory Assessment and Treatment) Act 1992 ("MH(CAT)Act") and the Intellectual Disability (Compulsory Care and Rehabilitation) Act 2003 (“ID(CCR)Act").

\section{A Therapeutic Dispositions: s 34 CP(MIP)Act}

Where a mentally impaired person has committed a serious or violent offence but their mental state is such that treatment, rather than incarceration, is justified, s 34 of the $\mathrm{CP}(\mathrm{MIP})$ Act allows the court to divert the offender into treatment, care, or rehabilitation. This transfers the offender from the jurisdiction of the Department of Corrections to that of the Ministry of Health.

The s 34 power is available where three threshold conditions are satisfied. First, the offender must have been convicted of an imprisonable offence. ${ }^{69}$ Therapeutic dispositions are not available for minor offending. Second, one or more health assessors must provide evidence that the offender's mental impairment requires compulsory treatment or care for the offender's own interests, the safety of the public, or the safety of

$67 \quad$ The "Mason Report" was a report released in 1988 following a commission of inquiry led by Judge Ken Mason into psychiatric services in New Zealand. It was the impetus for the development of forensic mental health services, services that cater for mentally ill criminal offenders: Ministry of Health Census of Forensic Mental Health Services 2005 (Wellington, 2007) at 1.

68 David Chaplow "Services for Mentally Abnormal Offenders: Some Important Issues" in Warren Brookbanks and Sandy Simpson (eds) Psychiatry and the Law (LexisNexis, Wellington, 2007) 383 at 387.

69 Criminal Procedure (Mentally Impaired Persons) Act 2003, s 34(1). 
a person or class of person. ${ }^{70}$ Third, one or more health assessors must provide evidence that the offender is "mentally disordered", ${ }^{71}$ or has an "intellectual disability". ${ }^{72}$ The terms "mental disorder" and "intellectual disability" are defined in the MH(CAT)Act and $\mathrm{ID}(\mathrm{CCR})$ Act respectively, meaning satisfaction of this third condition depends on the relevant provisions and jurisprudence of those two statutes.

Once these three prerequisites are satisfied, the court may order one of four therapeutic dispositions provided in s 34(1) of the CP(MIP)Act. There are two orders of differing severity for each category of mental impairment. These are known as "hybrid orders" or "purely therapeutic orders".

\section{A The hybrid order (s 34(1)(a))}

Section 34(1)(a) is the more severe or restrictive order. It allows the court to sentence the impaired offender to a term of imprisonment but simultaneously order detention as a "special patient" in a "hospital" under the MH(CAT)Act, ${ }^{73}$ or as a "special care recipient" in a "secure facility" under the ID(CCR)Act. ${ }^{74}$ This is known as a hybrid order" ${ }^{75}$ because it combines the normally separate concepts of punishment (in the form of a sentence of imprisonment) and therapy (in the form of an order for treatment). ${ }^{76}$ The order, by incorporating a finite term of imprisonment, allows the court to control the length of detention its subject will receive. ${ }^{77}$ As such, it is appropriate for mentally impaired offenders who are convicted of serious or violent offences, ${ }^{78}$ pose a high risk to the public, ${ }^{79}$ and for whom detention in prison is an insufficient risk reduction strategy (presumably on the basis that the risk posed is a result of the impairment, which cannot be addressed in prison). ${ }^{80}$ If the need for treatment or care ceases while under the $\mathrm{s}$ 34(1)(a) order, but the term of imprisonment has not yet expired, the offender is

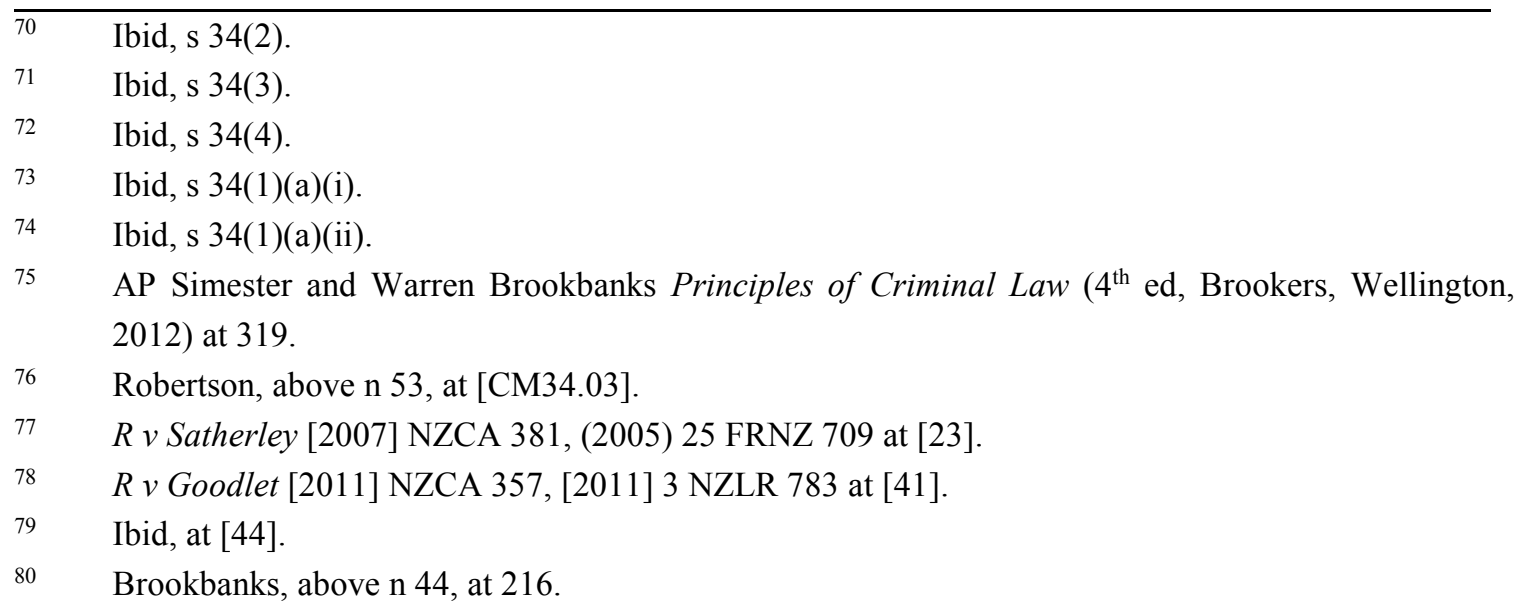


transferred to prison to complete the sentence. ${ }^{81}$ Conversely, if the sentence of imprisonment expires, but the need for treatment or care continues, the offender is reclassified a "patient" or "care recipient" and released in accordance with the civil release procedures specified in either the $\mathrm{MH}(\mathrm{CAT})$ Act or ID(CCR)Act. ${ }^{82}$

\section{B The purely therapeutic order (s 34(1)(b))}

Alternatively, the court can impose a "purely therapeutic" order under s 34(1)(b) of the CP(MIP)Act. ${ }^{83}$ This means the court does not sentence the offender and, instead, orders treatment as a "patient" under the $\mathrm{MH}(\mathrm{CAT}) \mathrm{Act},{ }^{84}$ or care as a "care recipient" under the ID(CCR)Act. ${ }^{85}$ Accordingly, the court relinquishes all control of the length of the offender's detention to the relevant clinicians. ${ }^{86}$ If the impairment is easily addressed, the offender's release may be granted after a relatively short period as compared with the term of imprisonment that would otherwise have been imposed. ${ }^{87}$ Conversely, if the impairment is relatively static, the length of the offender's "purely therapeutic" detention risks becoming disproportionate to the severity of their offending. ${ }^{88}$

This highlights the difficulty of reconciling the principle of proportionality with therapeutic orders, as the length of detention required for treatment bears no relationship to the offence, but instead to the impairment the offender labours under. However, given therapeutic orders exist to ensure offenders who need treatment or care actually receive it rather than languish in prison, ${ }^{89}$ some compromise to proportionality is surely acceptable.

$81 \quad$ Zainab Al-Alawi (ed) Brookers Family Law - Incapacity (online looseleaf ed, Brookers) at [MH2.27.24].

82 Sabine Visser "Assessment and Care of Offenders with Mental Impairment" in Fred Seymour, Suzanne Blackwell, and John Thorburn (eds) Psychology and the Law in Aotearoa New Zealand (New Zealand Psychological Society, Wellington, 2011) 193 at 199. Simester and Brookbanks, above n 75, at 320. Criminal Procedure (Mentally Impaired Persons) Act 2003, s 34(1)(b)(i). Ibid, s 34(1)(b)(ii). $R v$ Goodlet, above $\mathrm{n} 78$, at [23]. This risk, and the corresponding reluctance of some courts to order a therapeutic disposition (even where the offender clearly required it), was the impetus behind development of the s 34(1)(a) orders which were not available in the statutory predecessor to the CP(MIP)Act 2003: Criminal Justice Amendment Bill (No 7) 1999 (328-2) (select committee report) at 8.

Brookbanks, above $\mathrm{n} 44$, at 204.

Criminal Justice Amendment Bill (No 7) 1999 (328-2) (select committee report) at 9. 
Section 34(1)(b) orders are not available for all types of offending. Because a s 34(1)(b) order places the offender entirely outside the control of the justice system, the courts do not consider it appropriate for serious or violent offenders. The Court of Appeal has described the s 34(1)(b) order as a "more benevolent option" appropriate for "less serious offenders". 90 Accordingly, sexual or violent offending should only be addressed through a s 34(1)(a) order or a sentence of imprisonment. ${ }^{91}$ Thus, for the cohort of offenders that this paper addresses, the hybrid order is the only realistic disposition.

\section{Treatment and punishment: theoretical contradictions in the $\mathbf{s} 34$ orders}

Despite the obvious benefit in providing therapeutic diversion from prison for offenders with health needs, the s 34 orders are criticised as conceptually incoherent. This is largely because, notwithstanding their therapeutic intent, the orders have a punitive effect as they still result in a person's involuntary confinement. ${ }^{92}$

The hybrid orders in particular are seen to present this tension as they contain an explicit punitive component in including a finite sentence of imprisonment, which sits uneasily with a corresponding provision for treatment. Brookbanks considers that by simultaneously providing for treatment and punishment, the order "marries" together two incompatible notions. ${ }^{93}$ How can a court, on one hand, identify an offender's impairment as rendering them in need of compulsory care or treatment but, on the other, consider them an appropriate subject for a sentence of imprisonment? As identified above, mental impairment renders the traditional rationales of imprisonment futile as the mentally impaired person lacks the cognitive capacity to process the purpose of punishment or amend their behaviour in response to it. This means that the s 34(1)(a) order risks contravening the principles of sentencing and inappropriately subjecting mentally impaired persons to harsh penal sanctions.

While this theoretical tension is acknowledged, it is argued here that the s 34(1)(a) orders are justified. The orders strike a workable balance between two competing policy objectives presented by mentally impaired offenders, incapacitation and rehabilitation. In doing so, the orders ensure therapeutic dispositions are granted to violent and sexual offenders as well as to less serious offenders. Where a mentally impaired person has

\footnotetext{
$90 \quad R v$ Satherley, above $\mathrm{n} 77$, at [29].

91 Ibid, at [31].

92 Al-Alawi, above n 81, at [MH2.27.28].

93 Brookbanks, above n 44, at 217.
} 
committed sexual or violent offences, an indisputable need to protect the public from that person exists. Accordingly, the courts have a legitimate interest to ensure such offenders are not released earlier than is warranted by the nature of their offending. Simultaneously, the fact the offender is mentally impaired raises the need for treatment or care. For a court to satisfy both objectives some control over the nature and length of therapeutic detention is necessary and this is only provided with the hybrid order.

The historical use of therapeutic dispositions supports this. Before the introduction of the hybrid order, the courts were reluctant to grant therapeutic dispositions for serious sexual or violent offenders, even where they had clear treatment needs. ${ }^{94}$ Consequently, mentally impaired persons who had committed serious offences were imprisoned to ensure a minimum period of detention, despite imprisonment compromising rehabilitation, exacerbating the impairment, and restricting subsequent transfer into treatment or care. ${ }^{95}$ As such, the hybrid order ensures greater numbers of impaired offenders actually receive the treatment or care they need.

In sum, by allowing the court to retain control over the length of detention through imposing a sentence of imprisonment but simultaneously requiring treatment through a hospital order, a pragmatic balance between the need to provide treatment and the need to protect the public is achieved. To the extent this increases the numbers of impaired persons diverted from prison, the hybrid order is surely positive. Accordingly, some compromise to conceptual purity may be justified to ensure the courts actually employ therapeutic dispositions when sentencing serious sexual or violent offenders with health needs. While such persons face transfer to prison if their therapeutic needs are addressed before parole eligibility, this may not be inherently inappropriate given the severity of their index offence and the fact their mental impairment has first been ameliorated.

\section{Parameters on Therapeutic Dispositions: "Intellectual Disability” and "Mental Disorder"}

Eligibility for therapeutic dispositions is limited by the threshold definitions of "intellectual disability" or "mental disorder". An offender must satisfy one of these

\footnotetext{
$94 \quad$ Al-Alawi, above n 81, at [MH2.27.24]; Criminal Justice Amendment Bill (No 7) 1999 (328-2) (select committee report) at 8 .

95 Office of the Auditor General Performance Audit Report: Mental Health Services for Prisoners (2008) at [3.18] and [3.19].
} 
definitions before the court has jurisdiction to grant a s 34 order. ${ }^{96}$ This constraint on jurisdiction is interesting as, in all other respects, the CP(MIP)Act employs the wide and undefined term of "mental impairment" which applies, for example, when claiming unfitness to stand trial. ${ }^{97}$ However, therapeutic dispositions are restricted to these two forms of mental impairment and other potentially deserving categories of mental impairment, such as ABI, are excluded. The two qualifying definitions, and how they exclude ABI from the court's therapeutic jurisdiction, are discussed below.

\section{A The meaning of "intellectual disability"}

"Intellectual disability" is defined in s 7 of the ID(CCR)Act. The definition was developed by the American Association of Mental Retardation and is clinical rather than legal. ${ }^{98}$ It requires a person to have a "permanent impairment" with three characteristics: ${ }^{99}$ significantly sub-average general intelligence, ${ }^{100}$ as measured by an intelligence quotient (IQ) of 70 or less, ${ }^{101}$ significant deficits in adaptive functioning in at least two specified areas, ${ }^{102}$ such as self-care and social skills; ${ }^{103}$ and, finally, the impairment must have become apparent during the person's development, ${ }^{104}$ defined as being before the age of 18 years. ${ }^{105}$

The inclusion of an IQ measurement in the definition is controversial. ${ }^{106}$ IQ test results can vary depending on a person's stress levels or fatigue and also with environmental

\footnotetext{
96 Criminal Procedure (Mentally Impaired Persons) Act 2003, ss 34(3) and (4).

$97 \quad$ Ibid, s 4(1).

98 Olive Webb, Mhairi Duff and Mike Reed "Assessment and Care of Offenders with Intellectual Disabilities" in Fred Seymour, Suzanne Blackwell and John Thorburn (eds) Psychology and the Law in Aotearoa New Zealand (New Zealand Psychological Society, Wellington, 2011) 205 at 207. Intellectual Disability (Compulsory Care and Rehabilitation) Act 2003, s 7(1).

Ibid, s 7(1)(a).

Ibid, s 7(3).

Ibid, s 7(1)(b).

Ibid, ss 7(4)(b) and (d). Other adaptive functioning skills include communication, health and safety, leisure and work.

104 Ibid, s 7(1)(c).

105 Ibid, s 7(5).

10617 submissions to the Intellectual Disability (Compulsory Care) Bill (as it was then) raised issue with this part of the definition. The submitters were concerned about the standard testing used to determine IQ level, the narrowness of the IQ level, and the validity of IQ testing. These concerns did not change the ultimate definition used in the Act but did result in an amendment allowing a 5\% margin of error in testing: Intellectual Disability (Compulsory Care) Bill 1999 (329-2) (select committee report) at 4 .
} 
factors like time of day or place. ${ }^{107}$ As such, an intellectual disability can be "cured" upon re-testing, ${ }^{108}$ inappropriately shifting people inside and outside the therapeutic jurisdiction in a way that risks arbitrariness. In addition, the orthodox IQ tests are seen as biased against certain types of mental impairment, such as brain injury, where cognitive functioning is disturbed in a way that is not captured in the methodology of standard IQ tests. $^{109}$

\section{B ABI and intellectual disability}

While ABI and intellectual disability share some characteristics, ${ }^{110}$ the ID(CCR)Act's definition of intellectual disability excludes ABI from the therapeutic jurisdiction in two ways. First, $\mathrm{ABI}$ is specified in a list of conditions that, on their own, are excluded from the definition. ${ }^{111}$ To come within the definition, an ABI offender needs to have ABI as well as the other qualifying characteristics (making ABI a comorbidity to the intellectual disability). The explanatory note to the Intellectual Disability (Compulsory Care) Bill identified the reason for this exclusion was that $\mathrm{ABI}$ is "covered by the provisions of the Mental Health (Compulsory Assessment and Treatment) Act 1992", ${ }^{112}$ presumably making it unnecessary to include $\mathrm{ABI}$ in the new therapeutic regime. However, as explained below, ABI is not currently included within the scope of that Act.

The second way the definition excludes ABI is through the inclusion of the IQ measurement. An IQ test measures a person's ability to solve problems or answer questions relative to other people's ability to do the same. ${ }^{113}$ As such, it measures a form of cognitive capacity (intelligence based on the ability to reason) but not global cognition. This tends to exclude people with ABI, as demonstrated in $R v$ Satherley. ${ }^{114}$

Mr Satherley was a sexual offender with ABI resulting from a childhood car accident. He was found not to be intellectually disabled and so excluded from the therapeutic regime because his IQ was deemed (by a majority of clinicians) in excess of the upper limit of 70. However, one of the clinicians disputed the use of orthodox IQ tests on

\footnotetext{
$107 \quad$ Parliament of Victoria Law Reform Committee, above n 25, at 38.

108 Webb, Duff and Reed, above n 98, at 213.

$109 \quad R v$ Satherley, above n 77, at [9].

110 Parliament of Victoria Law Reform Committee, above n 25, at 40.

111 Intellectual Disability (Compulsory Care and Rehabilitation) Act 2003, s 8(1)(c).

112 Intellectual Disability (Compulsory Care) Bill 1999 (329-1) (explanatory note) at iii.

113 Parliament of Victoria Law Reform Committee, above n 25, at 36.

$114 \quad R$ v Satherley, above n 77.
} 
people with ABI. Dr Irwin identified that as people with ABI have damage to some, but not all, parts of the brain, they will be biased in orthodox IQ tests as these tests measure average performance across a range of sub-tests of specific brain areas. ${ }^{115}$ A person with $\mathrm{ABI}$ tends to display markedly varying results across the sub-tests because of the localisation of damage. ${ }^{116}$ This pushes their average up and provides them a higher IQ. ${ }^{117}$ As such, she advocated for the use of more complex neuropsychological tests to measure broader cognitive functioning and compensate for the orthodox test's internal bias against ABI. ${ }^{118}$ On the basis of these tests, $\mathrm{Dr}$ Irwin found $\mathrm{Mr}$ Satherley intellectually disabled. ${ }^{119}$ The Court of Appeal disagreed with this approach and indicated that, on the basis of the statutory terms, the assessment should be limited to orthodox tests determining intelligence and not broader tests determining cognitive capacity. ${ }^{120}$ As such, despite $\mathrm{Mr}$ Satherley having executive dysfunction, ${ }^{121}$ he did not have an intellectual disability and should not have been given a therapeutic disposition. ${ }^{122}$ The Court noted Mr Satherley should have been sentenced to imprisonment. ${ }^{123}$

\section{$1 \quad R v$ Satherley: wrong, but right}

The Court of Appeal's decision in $R v$ Satherley was arguably correct. While it restricts the definition of intellectual disability to those with a very severe form of cognitive impairment, this is consistent with the statute's strict terms, ${ }^{124}$ with the way practitioners understand the term, ${ }^{125}$ and with the different nature of treatment or care required for each form of cognitive impairment. ${ }^{126}$ People with ABI are likely to have had a much more diverse "lived experience" than people with a stereotypical form of intellectual disability

\footnotetext{
115 Ibid, at [9].

116 Ibid.

117 Ibid.

118 Ibid, at [10].

119 Ibid.

120 Ibid, at [20].

121 Ibid, at [16].

122 Ibid, at [20].

123 Ibid, at [32]. However, the Court of Appeal did not sentence Mr Satherley to imprisonment as he had responded well to the therapeutic regime in the interim period. Accordingly, he was given a community sentence so he could continue to access the rehabilitative programmes available. Section 7(2) of the ID(CCR)Act specifies intelligence should be "assessed by applying standard psychometric tests generally used by clinicians". Section 7(3) then specifies "general intelligence" should be measured as an intelligence quotient, rather than as cognitive functioning.

125 Interview with Hansen, above $\mathrm{n} 2$.

126 Interview with Foster, above n 2; Interview with Hansen, above n 2.
} 
such as Downs Syndrome, meaning their abilities and the way they define themselves will be quite different. ${ }^{127}$

In addition, while $\mathrm{ABI}$ is a permanent condition in the sense that damage to the brain cannot ever be completely undone, it has considerably more rehabilitation potential than intellectual disability. ${ }^{128}$ As such, people with ABI and people with intellectual disability should not necessarily receive equal dispositions or be classified as falling within a single framework. ABI and intellectual disability are more appropriately seen as two subgroups within an umbrella term of "cognitive impairment" rather than as synonymous conditions justifying equal treatment. ${ }^{129}$

Despite the technical correctness of excluding ABI from the definition of intellectual disability, Dr Irwin's broader approach is attractive from a policy perspective. $R v$ Satherley highlights the risk for people who, while clearly mentally impaired and in need of treatment, fall outside the jurisdictional definitions required for a therapeutic disposition. The Ministry of Health has itself identified that, in many cases, otherwise qualifying offenders are ineligible for therapeutic dispositions because their intellectual functioning is slightly higher than the statutory definition allows or their impairment is a result of ABI. ${ }^{130}$ Such people are consequently sent to prison where treatment or care is not guaranteed and where, by virtue of their mental impairment, they are vulnerable to harm. ${ }^{131}$ Therefore, having broad and flexible qualifying definitions that ensure people who need care or treatment actually receive it seems appropriate.

However, this really calls for the development of a broader therapeutic jurisdiction, rather than a widening of the classification of intellectual disability. Pushing larger groups of mentally impaired offenders into care for the intellectually disabled when they have different care and treatment needs is not a tenable solution to the problem.

\footnotetext{
127 Parliament of Victoria Law Reform Committee, above n 25, at 40.

128 Ibid, at 41.

129 Ibid, at 40 and 41.

130 Ministry of Health "Intellectual Disability (Compulsory Care and Rehabilitation) Act 2003" $<$ www.moh.govt.nz>.

131 Philip Brinded and Ceri Evans "Delivery of mental health services in prisons" in Warren Brookbanks and Sandy Simpson (eds) Psychiatry and the Law (Lexis Nexis, Wellington, 2007) 423 at 432; National Health Committee, above n 3, at [7.4.1].
} 


\section{The meaning of "mental disorder"}

The second threshold definition for a therapeutic disposition is "mental disorder" under the $\mathrm{MH}(\mathrm{CAT})$ Act. This is a particularly complex definition and, as such, has been the subject of considerable academic analysis. The complexity is, partly, a result of its application in the civil jurisdiction where the definition has been interpreted very widely to include conditions not recognised as orthodox psychiatric illnesses, such as personality disorder and brain injury. ${ }^{132}$ This is problematic as such conditions are not currently treatable in the psychiatric facilities an order under the $\mathrm{MH}(\mathrm{CAT})$ Act requires a patient to be detained in. By contrast, in the criminal jurisdiction the definition has been interpreted much more narrowly, with brain injury and personality disorder not accepted as mental disorders for the purpose of therapeutic dispositions on the basis that treatment for such conditions is not available in $\mathrm{MH}(\mathrm{CAT})$ Act facilities. ${ }^{133}$

It is argued here that the criminal jurisdiction's approach is preferable and the definition, in both jurisdictions, should be limited to conditions which are treatable in the facility the patient is to be detained in. Under this analysis, ABI is excluded from the current definition of mental disorder. This accords with the practice of criminal courts when considering an ABI offender's eligibility for therapeutic dispositions and is also consistent with the scheme and purpose of the MH(CAT)Act and the New Zealand Bill of Rights Act 1990 ("NZBORA"). This argument is developed below by first examining the definition of mental disorder, secondly, discussing "treatment" under the $\mathrm{MH}(\mathrm{CAT})$ Act, and then establishing why an additional requirement of "treatability" should be read into the definition. Finally, in subpart D, the exclusion of ABI from the definition of mental disorder is considered.

\section{The definition of "mental disorder" and its consequences}

Unlike the definition of "intellectual disability" in the $\operatorname{ID}(\mathrm{CCR})$ Act, the definition of "mental disorder" is legal rather than clinical. ${ }^{134}$ As such, its components do not

\footnotetext{
132 Sylvia Bell and Warren Brookbanks Mental Health Law in New Zealand (2nd ed, Brookers, Wellington, 2005) at 45; and see Ministry of Health $v M$, above $\mathrm{n} 36$; and see Re JAB MHRT 07/020, 20 March 2007.

133 See Blackwood $v R$ [2011] NZCA 143 and $R$ v Simmonds HC Christchurch CRI-2010-009-716, 11 November 2010.

134 Sylvia Bell "Defining Mental Disorder" in Warren Brookbanks and Sandy Simpson (eds) Psychiatry and the Law (Lexis Nexis, Wellington, 2007) 41 at 56.
} 
necessarily equate to recognisable clinical terms and no specific diagnosis is required for the term to be satisfied. ${ }^{135}$ The definition is as follows: ${ }^{136}$

... an abnormal state of mind (whether of a continuous or an intermittent nature), characterised by delusions, or by disorders of mood or perception or volition or cognition, of such a degree that it (a) poses a serious danger to the health or safety of that person or of others; or (b) seriously diminishes the capacity of that person to take care of himself or herself.

The definition contains two elements, both of which must be proved for the MH(CAT)Act's jurisdiction to be invoked. First, the assessed person must have an abnormal state of mind as determined by the presence of certain symptoms, such as delusions, or disorders of mood, perception, volition or cognition. ${ }^{137}$ Second, as a consequence of the abnormal state of mind, the person must constitute a danger to him or herself or to others, or must exhibit a seriously diminished capacity for self-care. ${ }^{138}$ However, a proven mental disorder does not automatically invoke the Act's coercive powers. Once a mental disorder has been established, the court must also be satisfied a compulsory treatment order is "necessary" (the necessity test). ${ }^{139}$

If these prerequisites are satisfied, the mentally disordered person will be subject to an "inpatient order" or a "community treatment order". If an inpatient order, the person is compulsorily treated in a "hospital", ${ }^{140}$ defined as a premise certified by the DirectorGeneral of Health to provide mental healthcare. ${ }^{141}$ In practice, this is a dedicated psychiatric hospital or a psychiatric ward in a general hospital. If a community treatment order, the person must accept treatment administered by a health practitioner in their own home or a community facility. ${ }^{142}$

\section{What is treatment?}

"Treatment" under the MH(CAT)Act has recently been interpreted as limited to clinical care that treats the "underlying cause" or "symptoms" of a mental disorder. ${ }^{143}$ This may

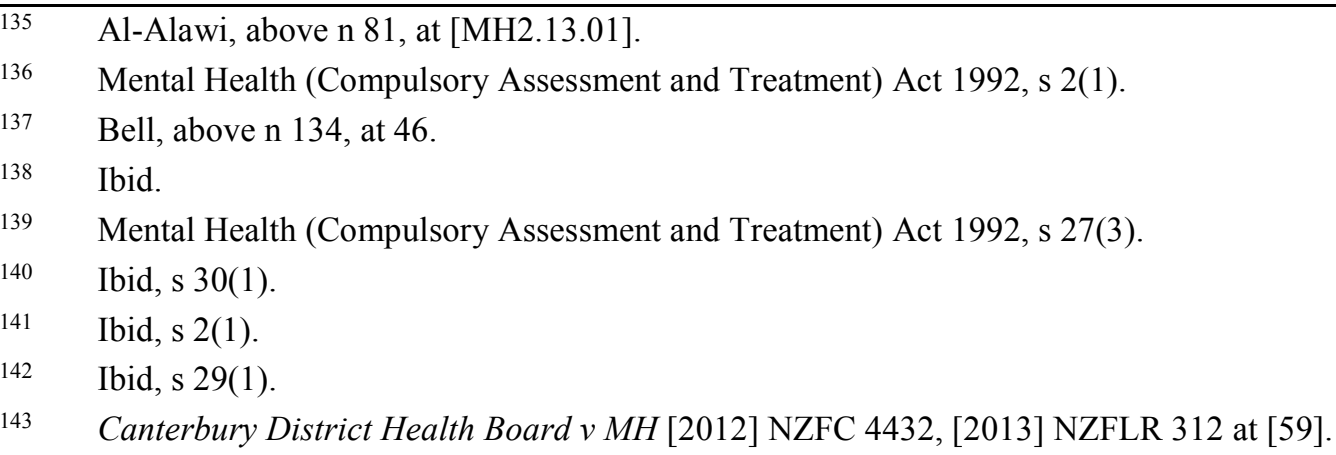


include pharmacological treatment, psychotherapy, counselling, occupational therapy, rehabilitation or nursing care. ${ }^{144}$ However, such treatment must be administered for the direct purpose of managing the mental disorder or be ancillary to such management. ${ }^{145}$ Treatment does not include the provision of healthcare solely or primarily for the purpose of ensuring physical care such as sanitation, feeding, or behaviour management. ${ }^{146}$ As such, legitimate treatment under the $\mathrm{MH}(\mathrm{CAT})$ Act is limited to healthcare which remedies the mental disorder that justified invoking the MH(CAT)Act's coercive powers.

\section{Interpreting "mental disorder" with a "treatability" requirement}

Because the definition of mental disorder is legal and not clinical it is appropriately shaped by principles of statutory interpretation. Two such principles are purpose and rights consistency. When applying these principles it becomes clear that, while no specific provision in the $\mathrm{MH}(\mathrm{CAT})$ Act requires it, the disorder's "treatability" in the facility the patient would be detained in should constrain whether the definition is satisfied in a given case.

\section{(a) Statutory purpose}

It is an elementary principle of statutory interpretation that legislative meaning should be identified in light of the statute's text and purpose. ${ }^{147}$ As such, the interpretation of "mental disorder" should be influenced by the purpose of the MH(CAT)Act and the text of its provisions. Purpose can be ascertained through a variety of factors, including the statute's long title, which reads: ${ }^{148}$

An Act to redefine the circumstances in which ... persons may be subjected to compulsory psychiatric assessment and treatment ... and generally to reform and consolidate the law relating to the assessment and treatment of persons suffering from mental disorder.

This indicates a key purpose of the $\mathrm{MH}(\mathrm{CAT}) \mathrm{Act}$ is to facilitate and regulate the treatment of mentally disordered persons. As such, for the statute's definition to be consistent with its purpose, it should result in treatment of the particular mental disorder

\footnotetext{
$144 \quad$ Ibid, at [60].

145 Ibid, at [59] and [60].

146 Ibid, at [68].

147 Interpretation Act 1999, s 5(1).

148 Mental Health (Compulsory Assessment and Treatment) Act 1992, Long Title (emphasis added).
} 
at issue, something not possible if the person is detained in a psychiatric hospital when not suffering from psychiatric illness.

The statutory text also illustrates the centrality of treatment to the $\mathrm{MH}(\mathrm{CAT}) \mathrm{Act}$ and, therefore, to its threshold definition. First, the term "compulsory treatment order" used throughout the $\mathrm{MH}(\mathrm{CAT}) \mathrm{Act}^{149}$ underscores the focus on treatment. It would do violence to language to invoke a "compulsory treatment order" in respect of a person who is untreatable in the facility an order requires their detention in. Other provisions whose text emphasises the centrality of treatment include s 27(4)(a) which requires a court, when imposing a community treatment order, to "be satisfied ... the service provides care and treatment ... appropriate to the needs of the patient". ${ }^{150}$ Treatment is again emphasised in s 30(1) where detention of a patient under an inpatient order is noted as "for the purposes of treatment". This demonstrates that one of the main purposes of the $\mathrm{MH}(\mathrm{CAT}) \mathrm{Act}$ is to ensure treatment of the persons subject to it. Accordingly, the meaning of "mental disorder" must be coloured by that purpose.

A number of decisions support this interpretation. In Waitemata Health $v$ Attorney General Elias CJ stated "[t]he only purpose of compulsory status is to achieve ... treatment". ${ }^{151}$ As such, in order for the definition to be consistent with its purpose, it must be a conduit to treatment. Similarly, in $R v$ Simmonds, Fogarty $\mathrm{J}$ found that the $\mathrm{MH}(\mathrm{CAT})$ Act could not be used to provide a therapeutic disposition for a mentally disturbed offender whose condition was not amenable to treatment. ${ }^{152}$ Fogarty $\mathrm{J}$ noted that psychiatrists providing assessments for the purposes of the Act "are reluctant to define a person as suffering from a mental disorder unless they think such a determination will assist in any treatment". ${ }^{153}$

Some decisions of the Mental Health Review Tribunal also support a requirement of treatability. In $\operatorname{Re} D G$ the Tribunal noted, "in considering the issue of mental disorder it is imperative that decision makers never lose sight of the benchmark of treatment", ${ }^{154}$ and considered the various symptoms of mental disorder specified in $\mathrm{s} 2(1)$ of the $\mathrm{MH}(\mathrm{CAT})$ Act must be "amenable to treatment" to "come within the Act". ${ }^{55}$ The

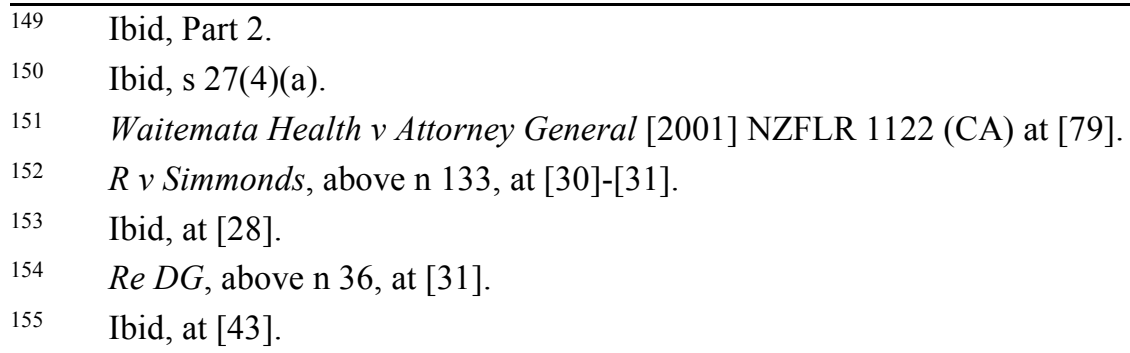


Tribunal held that "as it is the mental disorder which is subject to treatment, it is axiomatic that it must be amenable to treatment". ${ }^{156}$ Accordingly, the patient's ABIrelated executive dysfunction, for which no effective treatment was available in the psychiatric hospital he was detained in, did not amount to a "mental disorder" justifying compulsory treatment. ${ }^{157}$

\section{(b) Rights Consistency}

A second principle of statutory interpretation is rights consistency. ${ }^{158}$ As finding "mental disorder" satisfied where it does not result in appropriate treatment may result in a breach of rights, this also supports an interpretation of the definition in which treatment is a requisite component. Two rights illustrate this point: the right to treatment and the right to be free from arbitrary detention.

First, the MH(CAT)Act provides a right to "medical treatment and other health care appropriate to [the patient's] condition". ${ }^{159}$ This upholds relevant international principles which provide persons detained for mental health purposes with "the right to receive such health and social care as is appropriate to his or her health needs". ${ }^{160}$ Thus, while no right to treatment exists for general healthcare consumers, ${ }^{161}$ it is clearly applicable to persons detained under mental health legislation.

The rationale for this is twofold. First, when the state takes a person into its physical custody and thereby deprives that person of the ability to provide for his or her own needs, unique rights and duties arise in respect of that person. ${ }^{162}$ These rights and duties are principally for the purpose of preventing the detained person from experiencing suffering or harm while under physical control of an authority. ${ }^{163}$ The second reason relates to the purpose of the deprivation of liberty. A person detained under mental

\footnotetext{
$156 \quad$ Ibid, at [41].

157 Ibid, at [58].

158 New Zealand Bill of Rights Act 1990, s 6. International human rights law can also be used as an aide to statutory interpretation where statutory wording allows it: New Zealand Air Line Pilots' Association Inc v Attorney-General [1997] 2 NZLR 269 (CA) at 289. Mental Health (Compulsory Assessment and Treatment) Act 1992, s 66. United Nations Principles for the Protection of Persons with Mental Illness and for the Improvement of Mental Health Care GA Res 46/119, UN GOAR, 17 December 1991, Principle 8. See Shortland v Northland Health Ltd [1998] 1 NZLR 433 (CA). Fred Cohen "Captives' Legal Right to Mental Health Care" (1993) 17 Law and Psychol. Rev. 1 at 2. Ibid.
} 
health legislation is detained for the purpose of treatment. Accordingly, if such treatment is not provided, the reason for their detention is lost. ${ }^{164}$

The right to treatment means a treatability requirement should be interpreted as part of the definition of mental disorder. As discussed above, the definition provides jurisdiction for the Act's powers and, if it is found to be satisfied in respect of a person for whom treatment is not available in the facility the $\mathrm{MH}(\mathrm{CAT})$ Act requires their detention in, the person's right to treatment is automatically frustrated. Such a consequence could not have been Parliament's intention.

Second, the right to be free from arbitrary detention is affirmed in s 22 of the NZBORA. Arbitrary detention occurs where a person is detained unlawfully, unless the detention is necessary for safety. ${ }^{165}$ It also occurs where a person is detained lawfully, but the detention is unjustifiable as the original reasons for the detention are no longer valid; ${ }^{166}$ the detention is not based on "an adequate determining principle" or rationale; ${ }^{167}$ or it fails to comply with the statute granting the relevant detention power. ${ }^{168}$

Where a person is detained under the MH(CAT)Act (a detention for the purpose of treatment) but treatment cannot be provided in the relevant facility, the detention may be arbitrary on the basis that it lacks an appropriate rationale or breaches its empowering legislation. ${ }^{169}$ Without treatment, detention becomes purely custodial, yet custody is not an appropriate function of the health system. ${ }^{170}$ Purely custodial detention in a health facility would lack an adequate rationale and risk illegality. ${ }^{171}$ Equally, as discussed above, the $\mathrm{MH}(\mathrm{CAT})$ Act emphasises treatment and therefore detention without treatment may be ultra vires. This means that for detention under the mental health regime to be justified (and therefore not arbitrary) it should be "consequent on a treatable condition". ${ }^{172}$ As such, the right to be free from arbitrary detention also supports an

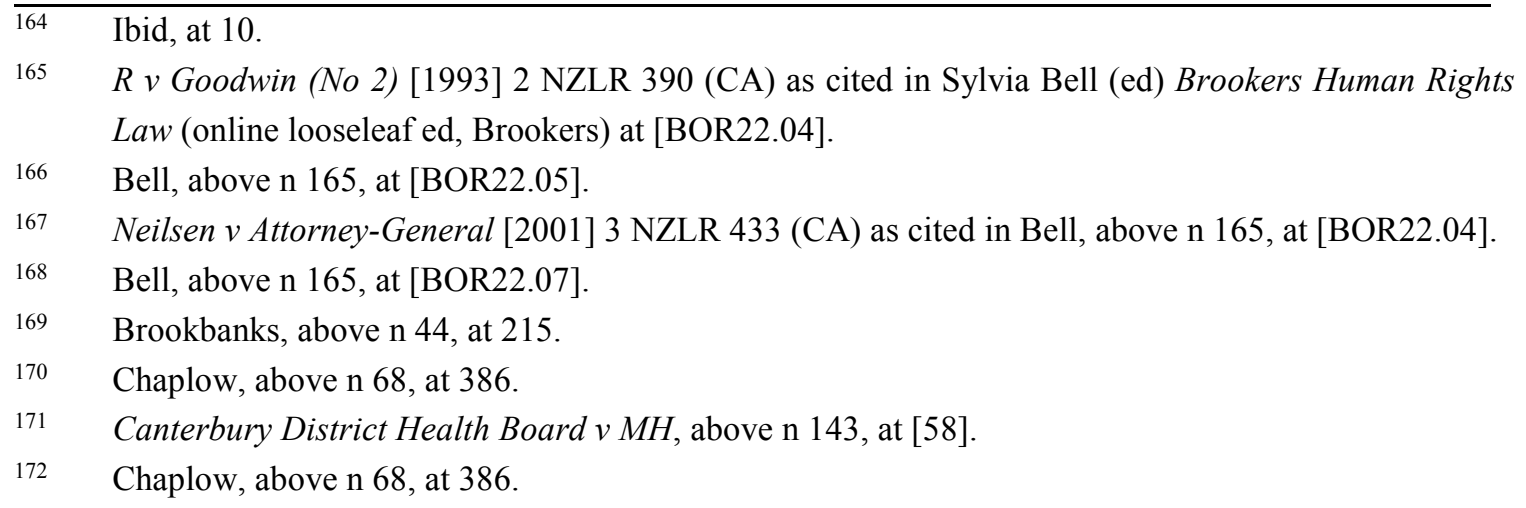


interpretation of "mental disorder" as requiring treatability in the facility the patient is detained in.

\section{Why treatability should be a component of mental disorder and not the necessity test}

The preceding sections of the paper have argued that treatability should be interpreted as a requirement of the definition of mental disorder. However, some academics argue a treatability requirement should not be interpreted as falling within the definition but, rather, within the separate necessity test. ${ }^{173}$ This is inappropriate.

The necessity test, axiomatically, asks whether compulsory treatment is necessary "in all the circumstances of the case". ${ }^{174}$ It is focused on questions such as whether compulsion is required to achieve treatment or whether voluntary compliance is viable, ${ }^{175}$ and whether the mentally disordered person has caregivers or family who could "contain the danger or compensate for seriously diminished capacity"176 rendering compulsory treatment unnecessary. As such, it is not a test that asks whether the mental disorder is treatable in the relevant facility but, rather, whether compulsion is required to achieve treatment.

Supporting this, the necessity test only applies when the court grants a compulsory treatment order. It is not part of the test for release from compulsory status, which has been held by the Court of Appeal to be based solely on whether or not the person is, or remains, "mentally disordered". ${ }^{177}$ In addition, the Mental Health Review Tribunal has held a person for whom treatment is no longer efficacious should be released from compulsory status. ${ }^{178}$ This is logical as without the ability to release a person when treatment is unsuccessful, they could be detained indefinitely.

As such, if treatability was found to fall within the necessity test, rather than the definition of mental disorder, a person's lack of response to treatment, or the unavailability of treatment, would not be legitimate grounds for release. If the person continued to present an abnormal state of mind but could not be treated under the Act, they could be detained in perpetuity, risking arbitrary detention. A person who poses a

\footnotetext{
$173 \quad$ Al-Alawi, above n 81, at [MH2.13.02].

174 Mental Health (Compulsory Assessment and Treatment) Act 1992, s 27(3).

175 Nigel Dunlop “Compulsory Psychiatric Treatment and Mental Disorder" [2006] NZLJ 225 at 229.

$176 \quad$ Waitemata Health $v$ Attorney General, above n 151, at [86].

177 Ibid, at [79] and [90].

$178 \operatorname{Re} D G$, above $\mathrm{n} 36$, at [58].
} 
risk of harm, but who cannot be treated, is an appropriate candidate for some form of preventive detention, but not for detention in a treatment facility. ${ }^{179}$ As such, the availability of treatment in the facility a person is to be detained in should be a component of the definition of mental disorder, facilitating exit from the MH(CAT)Act's regime where treatment is not efficacious, as well as where it is successful and the disorder has abated.

\section{How a treatability requirement may impact the civil jurisdiction}

While the civil jurisdiction is outside the scope of this paper, placing a limitation on the definition of mental disorder in the MH(CAT)Act would also limit its scope. The $\mathrm{MH}(\mathrm{CAT})$ Act's civil jurisdiction is used to order compulsory treatment for non-offenders (and offenders who commit non-imprisonable offences) whose mental state is such that they pose a risk to themselves or others. ${ }^{180}$ A treatability requirement may mean "untreatable" mental illnesses, such as personality disorder, ${ }^{181}$ and disorders for which treatment services are not currently provided in MH(CAT)Act facilities, such as brain injury, ${ }^{182}$ are excluded from the Act. Persons with these conditions would therefore not be able to be detained when exhibiting high risk behaviour.

Notwithstanding this, the requirement for treatability should still be pursued. As demonstrated above, the MH(CAT)Act's purpose is to facilitate treatment (and assessment for the purpose of treatment), not to detain people with antisocial behaviour who have not committed a criminal offence warranting custody. If the MH(CAT)Act is used to detain such persons under civil orders, it risks being a vehicle for arbitrary detention. ${ }^{183}$ The use of the MH(CAT)Act's civil jurisdiction in respect of brain injury is discussed at subpart D4 below and expands on this discussion.

\section{ABI and "mental disorder"}

While ABI-related executive dysfunction manifests some of the phenomenology of a "mental disorder", it falls outside the definition's current scope. This is because treatment for ABI-related executive dysfunction (as opposed to a comorbid mental

\footnotetext{
$179 \quad R v$ Simmonds, above n 133, at [31].

$180 \quad$ Ministry of Health $v M$, above $\mathrm{n} 36$.

$181 \quad R v$ Simmonds, above n 133, at [30].

182 Blackwood $v R$, above n 133, at [23]-[26].

183 It is surprising that the use of civil compulsory treatment orders for conditions such as brain injury have not yet been legally challenged as constituting arbitrary detention.
} 
illness) is not currently provided in the hospitals an inpatient order diverts offenders into. Accordingly, while ABI has significant rehabilitation potential, ${ }^{184}$ it is an "untreatable" condition under the current $\mathrm{MH}(\mathrm{CAT})$ Act regime and so falls outside the gateway definition. This means ABI offenders are excluded from the court's therapeutic jurisdiction. The reasons for this are examined below.

\section{Security classifications and secure treatment facilities}

When transferred from the justice to health jurisdiction (either when transferred from prison $^{185}$ or when given a therapeutic disposition) an offender must be held as an "inpatient". ${ }^{186}$ The inpatient status means the person is subject to restrictions on their liberty while detained in the facility. As such, where persons are held as inpatients, the treatment centre effectively provides both a custodial function and a therapeutic one. A person who receives a hybrid order receives an additional security classification, the categorisation as a "special patient". ${ }^{187}$ This flags that person as one who not only has restrictions on their day-to-day liberty but who also cannot be released solely when the clinician deems them therapeutically ready as occurs for other inpatients. ${ }^{188}$

Inpatients and special patients must be detained for treatment in a "hospital". ${ }^{189}$ A "hospital" is a premise certified by the Director-General of Health to provide mental healthcare, in compliance with service standards and any conditions imposed by the Director-General. ${ }^{190}$ In practice, this means inpatients and special patients are detained and treated in forensic mental health units, the only "hospitals" with the necessary security certification to house criminal offenders. ${ }^{191}$ There are six such units in New

$184 \quad$ Interview with Foster, above $\mathrm{n} 2$.

185 See Mental Health (Compulsory Assessment and Treatment) Act 1992, s 46. This provision provides the chief executive of the Department of Corrections with a power to transfer a prisoner into a "hospital" for the purpose of psychiatric treatment or care.

186 Robertson, above n 53, at [CM34.04].

187 Criminal Procedure (Mentally Impaired Persons) Act 2003, s 34(1)(a)(i).

188 Robertson, above n 53, at [CM4.15.01].

189 Mental Health (Compulsory Assessment and Treatment) Act 1992, s 30(1); Criminal Procedure (Mentally Impaired Persons) Act 2003, s 31(1)(a)(i).

190 See Mental Health (Compulsory Assessment and Treatment) Act 1992, s 2(1) and Health and Disability Services (Safety) Act 2001, s 9.

191 Email and telephone conversation with Maren Frerichs, Senior Advisor, Mental Health Protection, Office of the Director of Mental Health, Ministry of Health, 26 June 2013. 
Zealand, ${ }^{192}$ which primarily house and treat people with severe psychiatric conditions such as schizophrenia, bipolar affective disorder, and psychosis. ${ }^{193}$

\section{How ABI is untreatable under the MH(CAT)Act}

Rehabilitation for ABI-related executive dysfunction is not specifically provided in any of the six forensic mental health units. ${ }^{194}$ There is also no ABI rehabilitation facility in New Zealand that can provide the security necessary to fulfil the custodial, as well as therapeutic, functions involved in treating special patients. ${ }^{195}$ There are, of course, dedicated ABI rehabilitation centres that provide treatment to the non-offending population. ${ }^{196}$ However, such services cannot accept criminal offenders, and do not accept patients referred under the $\mathrm{MH}(\mathrm{CAT})$ Act regime because of the risk posed to other patients. ${ }^{197}$ Accordingly, there is a gap in the health system for offenders with ABI as no secure facilities exist to which they can be diverted under a therapeutic disposition (or indeed under an inpatient order issued in the MH(CAT)Act's civil jurisdiction).

Because ABI cannot be treated in inpatient facilities under the current $\mathrm{MH}(\mathrm{CAT}) \mathrm{Act}$ regime, it falls outside the gateway definition of mental disorder. Where the definition is not a conduit to treatment it fails to meet its statutory purpose and risks amounting to arbitrary detention. A person should not be classified as mentally disordered solely for a custodial purpose, as this is the function of the corrections system and not the health system. Equally, psychiatric units are inappropriate places to house people with ABIrelated executive dysfunction. ${ }^{198}$ Such people have specific treatment and rehabilitation needs deriving from $\mathrm{ABI}$ and are therefore not best treated as general psychiatric patients. ${ }^{199}$ Housing people with ABI in psychiatric units may increase their stress and result in social stigmatisation, impeding rehabilitation and reintegration back into the

\footnotetext{
192 Ministry of Health, above n 67, at 3.

193 Ibid, at 17.

194 As identified by the author examining the treatment services listed on each facility's website.

195 Blackwood $v$ R, above $\mathrm{n}$ 133, at [24] and [26].

196 Auckland based “ABI Rehabilitation” is the leading example. See <www.abi-rehab.co.nz>.

197 Interview with Foster, above n 2.

198 Capital and Coast District Health Board Central Regional Forensic Mental Health Services: Draft 5 Year Development Plan (2007) at 7; Chaplow, above n 68, at 385; Interview with Hansen, above n 2.

199 Interview with Hansen, above n 2; Interview with Foster, above n 2.
} 
community. ${ }^{200}$ It is therefore appropriate that ABI is excluded from the definition of mental disorder under the current $\mathrm{MH}(\mathrm{CAT})$ Act regime.

For completeness, a caveat to the above discussion should be noted. As identified in Part III, ABI can cause psychosis or lead to other mental illness such as schizophrenia or bipolar disorder. ${ }^{201}$ When this is the case, classification as "mental disorder" under the $\mathrm{MH}(\mathrm{CAT}) \mathrm{Act}$ is appropriate. In such a situation, the definition is a conduit to treatment, as psychiatric care in certified hospitals is appropriate treatment for such conditions. ${ }^{202}$ However, in the more common cases, where ABI leads to executive dysfunction, psychiatric care is not best practice and the preceding argument stands.

\section{Blackwood $v$ R: an illustration of the problem}

Unlike in the civil jurisdiction, $\mathrm{ABI}$ has never been found to satisfy the definition of mental disorder for a therapeutic disposition under s 34 of the CP(MIP)Act. ${ }^{203}$ This gap in the therapeutic jurisdiction is well illustrated by Blackwood $v R$.

Jesse Blackwood was involved in a serious car accident when he was 18 years old and suffered a TBI. ${ }^{204}$ As a consequence, he developed executive dysfunction including cognitive deficits such as slowness in information processing, memory problems and inflexible thinking patterns; socio-adaptive problems including difficulties in socialcommunication; and volitional problems including impulsivity and deficits in selfmonitoring and self-correcting his behaviour. ${ }^{205}$

One year after his accident, Mr Blackwood committed an act of sexual violation by rape against his former girlfriend. ${ }^{206}$ He appeared to show little understanding that what he had done was wrong and, over the course of his conviction and sentencing, reverted

\footnotetext{
$200 \quad$ Interview with Hansen, above $\mathrm{n} 2$.

201 Interview with Duane McWaine, Psychiatrist (the author, 21 July 2013).

202 See for example $\operatorname{Re} C$ MHRT08/057, 26 May 2008 where a person subject to a compulsory treatment order had a psychotic disorder, dementia, and hyper-sexuality secondary to head injury. As such, the subject person in this decision was treatable by psychiatric services and so appropriately classified as mentally disordered under the MH(CAT)Act.

203 As discoverable in standard searches of the case law databases.

204 Blackwood $v R$, above $\mathrm{n}$ 133, at [6].

205 Ibid, at [7].

206 Ibid, at [1].
} 
between accepting responsibility for the offending and expressing remorse, ${ }^{207}$ and denying the offending had happened at all. ${ }^{208}$ Mr Blackwood's executive dysfunction also meant he posed a risk of harm to others: he had difficulty controlling his behaviour, had not accepted his wrongdoing, and posed a risk of recidivism for both sexual and violent offending. ${ }^{209}$

Three psychological experts engaged by the court were unanimous Mr Blackwood's ABI played "some role" in the offending. ${ }^{210}$ Further, the experts were unanimous he required specialist brain injury rehabilitation to address his cognitive and behavioural difficulties, ${ }^{211}$ and to reduce the risk of harm he posed to the public as a consequence of his executive dysfunction. ${ }^{212}$ All the experts also identified prison was inappropriate for Mr Blackwood as he could not receive the necessary treatment there, ${ }^{213}$ and would be at a high risk of harm from other inmates due to his behaviour. ${ }^{214}$

This fact pattern reveals Mr Blackwood as an offender presenting clear therapeutic need, making him an appropriate candidate for a therapeutic disposition to ensure treatment for his impairment in a secure environment. The Court of Appeal acknowledged this was the case. $^{215}$ However, because his mental impairment resulted from ABI, Mr Blackwood "fell between the cracks" of the court's therapeutic jurisdiction, ${ }^{216}$ and as such, rather than being treated in a therapeutic regime, he was imprisoned. The reasons for this are discussed below.

First, Mr Blackwood fell outside the definition of intellectual disability. ${ }^{217}$ His ABI occurred at the age of 18 (and was therefore outside the "developmental" stage) and his IQ was in excess of the maximum limit of 70. Second, Mr Blackwood fell outside the definition of mental disorder. The expert health assessors differed in their individual

\begin{tabular}{ll}
\hline 207 & Ibid. \\
208 & Ibid, at [fn 7]. \\
209 & Ibid, at [37]. \\
210 & Ibid, at [29]. \\
211 & Ibid, at [10]. \\
212 & Ibid, at [37]. \\
213 & Ibid. \\
214 & Ibid, at [36], [41], [47], [48]. \\
215 & Ibid, at [19]. \\
216 & Ibid, at 5. \\
217 & Ibid, at [21].
\end{tabular}


assessment of Mr Blackwood on this ground. ${ }^{218}$ However, the Court of Appeal noted that as ABI-related executive dysfunction could not be treated under the MH(CAT)Act regime, ${ }^{219}$ reconciling the differing views of the experts on whether he met the phenomenology of mental disorder under the MH(CAT)Act was unnecessary. ${ }^{220}$ Diversion into a forensic mental health unit would be "inappropriate for the current needs of $\mathrm{Mr}$ Blackwood, which are specifically related to acquired executive dysfunction. Thus, a mental healthcare facility ... is not a suitable ongoing treatment setting for someone with traumatic brain injury". 221

As such, the Court of Appeal implicitly applied a treatability requirement to the definition of mental disorder and found Mr Blackwood fell outside its therapeutic jurisdiction as his mental impairment was untreatable in the current therapeutic regime. The Court of Appeal noted its surprise at the absence of any secure ABI rehabilitation facility in New Zealand, given the numbers of brain injured offenders in this country. ${ }^{222}$ However, this meant the Court had no choice but to sentence Mr Blackwood to a term of imprisonment, despite the recognised inappropriateness of that course of action. ${ }^{223}$

Blackwood $v R$ illustrates a problem with the current therapeutic jurisdiction. As ABI is untreatable in secure $\mathrm{MH}(\mathrm{CAT})$ Act facilities, and explicitly excluded from the $\mathrm{ID}(\mathrm{CCR})$ Act, it is effectively excluded from the court's therapeutic jurisdiction. Consequently, persons like Mr Blackwood who suffer from an obvious mental impairment that renders them unsuitable for prison and in need of treatment are ineligible for therapeutic sentences. In the circumstances, the best the Court could do was mitigate Mr Blackwood's sentence so as to make him eligible for parole earlier and flag the need for treatment to the Parole Board, in the hope the Board would grant him parole on the condition he attend community-based ABI rehabilitation. ${ }^{224}$

However, even with this relatively sympathetic approach, Mr Blackwood was subject to a sentence of four years and three months' imprisonment, a significant period to wait for treatment, even if mitigated by early parole. ${ }^{225}$ The experts engaged in the case noted a

\begin{tabular}{ll}
\hline 218 & Ibid, at [22]. \\
219 & Ibid, at [23]-[26]. \\
220 & Ibid, at [22]. \\
221 & Ibid, at [24]. \\
222 & Ibid, at [fn 6]. \\
223 & Ibid, at [40]. \\
224 & Ibid, at [42]. \\
225 & Ibid, at [45].
\end{tabular}


risk this delay would "increase the challenges for Mr Blackwood" in achieving his longterm rehabilitation. ${ }^{226}$ In addition, on the basis of interviews conducted for this research, it is unclear whether community-based rehabilitation services would even accept $\mathrm{Mr}$ Blackwood, given the risk posed to the non-offender patient population. ${ }^{227}$ This clearly underscores the need to establish secure ABI rehabilitation centres that high risk persons can be detained and treated in.

\section{ABI as a mental disorder for the purpose of civil commitment}

In contrast to the criminal jurisdiction, a small number of decisions in the civil jurisdiction have found the definition of mental disorder satisfied by people with ABI. As the MH(CAT)Act's threshold definition should be the same for both jurisdictions, two of these decisions, Re JAB and Ministry of Health $v M$, are discussed. ${ }^{228}$ These decisions, while demonstrating a pragmatic or creative approach to the problem of ABI in the $\mathrm{MH}(\mathrm{CAT})$ Act regime, risk misuse of the $\mathrm{MH}(\mathrm{CAT})$ Act's powers. Rather than squeezing people exhibiting risky behaviour into a framework inappropriate for their needs, the Mental Health Review Tribunal and its appellate courts ought to exclude these cases from its jurisdiction and flag the problem with the Ministry of Health so appropriate treatment facilities can be established to cater for both offenders and non-offenders with ABI.

In $\operatorname{Re} J A B$ and Ministry of Health $v M$ the Tribunal and appellate court, respectively, found the definition of mental disorder satisfied by ABI. Their reasoning was as follows. First, the phenomenological limb was satisfied as the subject person's executive dysfunction manifested symptoms consistent with disordered cognition. ${ }^{229}$ The second dangerousness limb was also met, as the subject person either constituted a danger to others through their violent behaviour, ${ }^{230}$ or presented a seriously diminished capacity for self-care. ${ }^{231}$ Accordingly, both elements of the definition were satisfied, as was the necessity test, and therefore, inpatient orders were issued.

However, in both cases the decision-maker acknowledged the treatment needs of the patient could not be provided in the psychiatric hospital at which he was to be

\footnotetext{
$226 \quad$ Ibid, at [46].

227 Interview with Foster, above $\mathrm{n} 2$.

$228 \operatorname{Re} J A B$, above n 132; Ministry of Health $v M$, above $\mathrm{n} 36$.

$229 \operatorname{Re} J A B$, above n 132, at [25]; Ministry of Health $v M$, above $\mathrm{n} 36$, at [17].

$230 \operatorname{Re} J A B$, above $\mathrm{n} 132$, at [25]; Ministry of Health $v M$, above $\mathrm{n} 36$, at [23] and [25].

$231 \operatorname{Re} J A B$, above n 132, at [18]; Ministry of Health $v M$, above $\mathrm{n} 36$, at [17] and [25].
} 
detained. ${ }^{232}$ In $R e J A B$ the Tribunal noted the person "was not well placed in hospital",233 and the expert clinician stated it "was not an appropriate setting for him". ${ }^{234}$ Despite this, the order was seen as important to secure custody, with the expectation that communitybased ABI treatment could subsequently be provided. ${ }^{235}$ These cases demonstrate the inadequacy of the current $\mathrm{MH}(\mathrm{CAT}) \mathrm{Act}$ regime for $\mathrm{ABI}$. Inpatient orders do not result in the subject person's treatment as there are no secure hospitals certified under the $\mathrm{MH}(\mathrm{CAT}) \mathrm{Act}$ that provide ABI rehabilitation. Accordingly, the orders, rather than being therapeutic become solely custodial and simply serve a risk-management function. This misuses the $\mathrm{MH}(\mathrm{CAT})$ Act's powers, which are designed for the purpose of achieving treatment, and means compulsory treatment orders become a vehicle for rights violations.

On this basis, conditions that are not treatable under the MH(CAT)Act regime should fall outside its threshold definition. The inadequacy of the MH(CAT)Act regime to cater for $\mathrm{ABI}$ is a policy problem that requires action by the Ministry of Health and not a creative but inappropriate use of dispositions by decision-makers. While this more restricted approach may have unfortunate results in an individual case (such as the imprisonment of an impaired person), the approach taken by the criminal courts as evidenced in Blackwood $v R$ is more appropriate.

\section{Imprisoning ABI Offenders: Why the Therapeutic Jurisdiction Needs Reform}

The current exclusion of serious ABI offenders from the court's therapeutic jurisdiction means they are subject to imprisonment. However, imprisoning ABI offenders also raises issues. Such persons have high health needs, often requiring specialist neurological rehabilitation which may involve medical or psychiatric treatment, cognitive behavioural therapy, physiotherapy, occupational therapy, speech therapy and counselling. ${ }^{236}$ In addition, prisoners with ABI often pose behavioural issues for custodial staff. Due to cognitive deficits, ABI offenders may struggle to understand

\footnotetext{
$232 \operatorname{Re} J A B$, above $\mathrm{n} 132$, at [18] and [23]; Ministry of Health $v M$, above $\mathrm{n}$ 36, at [21].

$233 \operatorname{Re} J A B$, above n 132, at [23].

234 Ibid, at [18].

235 Ministry of Health $v M$, above $\mathrm{n} 36$, at [30] and [34]; Re JAB, above $\mathrm{n} 132$, at [25].

236 Suzanne Brown and Glenn Kelly Issues and Inequities Facing People with Acquired Brain Injury in the Criminal Justice System (Victorian Coalition of ABI Service Providers Inc, Brunswick, Victoria, 2012) at [6.6].
} 
prison rules and have difficulty following instructions. ${ }^{237}$ Due to impulsivity and increased aggression, they may become violent when confronted by prison staff or other inmates. $^{238}$ This leads to increased fights and assaults (where the ABI offender is either perpetrator or victim) and the increased use of in-prison disciplinary measures such as physical restraints or punishments. ${ }^{239}$ As such, imprisoning ABI offenders (whether the prison service is aware an inmate has $\mathrm{ABI}$ or not) strains prison staff and resources.

In light of the above, it is argued here that the court's therapeutic jurisdiction needs to be expanded to better accommodate ABI offenders and avoid their imprisonment. The argument is based on three grounds. First, prisoners' statutory right to treatment in s 75 of the Corrections Act 2004, arguably breached by the status quo. Second, the potential for imprisoning ABI offenders to constitute ill treatment, violating the NZBORA. Third, an analogy is drawn between the current position of ABI offenders and the preID(CCR)Act position of intellectually disabled offenders, to demonstrate why expanding the therapeutic regime is appropriate on policy grounds.

\section{A Prisoners' right to treatment and healthcare in prison}

As with mental health detainees, prisoners have a right to treatment that does not exist for the general population. This is provided in s 75 of the Corrections Act 2004 which states prisoners are "entitled to receive medical treatment that is reasonably necessary". ${ }^{240}$ This treatment must be "reasonably equivalent to the standard of health care available to the public" (the equivalence of care principle). ${ }^{241}$ The right to treatment reflects international principles, ${ }^{242}$ and is an effort by the state to realise its duties when depriving a person of liberty. Deprivation of liberty prevents a person from accessing healthcare for themselves and, accordingly, when the state exercises its power of incarceration, it assumes a duty to provide all necessary care to ensure the incarcerated person's needs are met. $^{243}$ As such, a prisoner's right to treatment is matched by a corresponding duty on

\footnotetext{
$237 \quad$ Ibid, at [6.3].

238 Ibid.

239 Ibid.

240 Corrections Act 2004, s 75(1).

241 Ibid, s 75(2).

242 United Nations Standard Minimum Rules for the Treatment of Prisoners ESC Res 663 C I (XXIV), UN ESCOR (1957).

243 National Health Committee, above n 3, at 42; Cohen, above n 162, at 2.
} 
the state to ensure such treatment is provided. If treatment is not provided, a prisoner may be able to argue breach of statutory duty or a rights violation. ${ }^{244}$

\section{The delivery of healthcare in prison}

In New Zealand, in-prison healthcare is delivered through a complex system. The Department of Corrections holds responsibility for delivering prisoners' primary healthcare. $^{245}$ This includes general frontline health services and primary mental health services normally obtained through a general practitioner or community nurse. ${ }^{246}$ The Ministry of Health has general responsibility for providing prisoners' secondary and tertiary health services. ${ }^{247}$ The Ministry of Health provides this through District Health Boards ("DHBs") who offer specialist medical care, hospital and complex surgical care, alcohol and drug services, and specialist mental health services. ${ }^{248}$ However, access to these services requires referral from a general practitioner, ${ }^{249}$ making it contingent on access to quality primary health services that identify need. Finally, the Accident Compensation Corporation also provides secondary and tertiary health services for prisoners $^{250}$ where treatment or rehabilitation is required for an illness or injury satisfying s 26 of the Accident Compensation Act 2001.251 However, as with DHB-funded secondary or tertiary care, specialist treatment for prisoners through the Accident Compensation regime requires the prisoner to be referred through an in-prison primary health provider and so access to treatment is again contingent on the quality of primary healthcare available.

\footnotetext{
$244 \quad$ The success of any such claim is obviously uncertain.

245 National Health Committee, above n 3, at 39.

246 Department of Corrections Prison Health and Disability Service Specifications (2002) at 2.

247 National Health Committee, above n 3, at 39.

248 Department of Corrections, above n 246, at 2.

249 Ibid.

$250 \quad$ National Health Committee, above n 3, at 39.

251 Stephen Todd "Accident Compensation and the Common Law" in The Law of Torts in New Zealand (6th ed, Thomson Reuters, Wellington, 2013) 21 at 42. Prisoners lose any entitlement to monetary compensation under the Accident Compensation regime when they are incarcerated but do not lose their entitlement to treatment or rehabilitation services unless the personal injury was acquired during the course of committing an offence: Accident Compensation Act 2001, ss 121(1) and 122(1).
} 


\section{ABI rehabilitation in prison: a breach of the right to treatment}

The current provision of healthcare for prisoners with $\mathrm{ABI}$ may breach the right to treatment in s 75 of the Corrections Act 2004. This is illustrated by two points: inadequate identification of need and lack of equivalence of care. First, a prisoner with $\mathrm{ABI}$ is unlikely to be identified as suffering from $\mathrm{ABI}$ while in prison and, therefore, is unlikely to be referred to the necessary specialist care, compromising the right to treatment. Unlike for other health conditions, the Department of Corrections has no systematic in-prison identification of neurological damage. ${ }^{252}$ Therefore, unless prison medical staff identify an obvious need or the prisoner self-reports, ABI will be undetected in the prison health system. By contrast, when prisoners enter prison they are comprehensively screened for mental illness to ensure appropriate treatment. ${ }^{253}$ Given the difficulty identifying ABI's many "silent symptoms", ${ }^{254}$ it is unlikely ABI will be detected or treated without such a specialist screening tool being employed.

The lack of in-prison ABI screening may violate the statutory right to treatment. Access to healthcare is highly dependent on adequate identification and assessment of need. ${ }^{255}$ Accordingly, a right to diagnosis may well constitute part of the right to treatment as its essential prerequisite. This means the inadequate in-prison screening of ABI-related issues, as the necessary first step in ensuring those issues are treated, may breach the right to treatment.

However, it could also be argued that the right to treatment in s 75 of the Corrections Act 2004 is limited to identified health problems and, therefore, a failure to identify a complex health need such as ABI does not breach the state's obligations. In the author's view, this is flawed for three reasons. First, as noted, identification is central to treatment. When a person attends their general practitioner they do so to receive a diagnosis as well as to receive treatment and so divorcing the two would create an artificial limit on the concept of treatment in the Corrections Act 2004. Second, as noted, the right to treatment reflects international standards for the treatment of prisoners, ${ }^{256}$

\footnotetext{
$252 \quad$ National Health Committee, above $\mathrm{n} 3$, at 89.

253 See Department of Corrections Mental Health Screening Tool, Primary Mental Health Services and Packages of Care Policy and Procedure (Policy Number 3-14, 2013). This screening tool has no ABI-related questions.

254 Interview with Foster, above $\mathrm{n} 2$.

255 National Health Committee, above n 3, at 89.

256 United Nations Standard Minimum Rules for the Treatment of Prisoners ESC Res 663 C I (XXIV), UN ESCOR (1957).
} 
affirmed in the Corrections Act 2004 itself. $^{257}$ These international standards specify a prison medical officer should examine every prisoner upon admission "with a view particularly to the discovery of physical or mental illness". ${ }^{258}$ This shows that the international standards the Corrections Act purports to implement envisage diagnosis or detection of health issues as part of prisoners' right to treatment. Third, the prison environment is not conducive to prisoners self-reporting health issues. Prisoners are reluctant to display vulnerability or engage in help-seeking behaviour, a consequence of the aggressive culture of prison life, ${ }^{259}$ and to avoid placement in an at-risk unit, perceived as a punitive measure by prison inmates. ${ }^{260}$ As such, prisoners are unlikely to independently seek treatment for self-identified cognitive deficits, impulsivity, or other ABI symptoms. This means, if prisoners' health is to be maintained, and the right to treatment realised, identification of need must be an obligation on the state and not the individual prisoner.

Even if a prisoner's ABI needs are identified, the current regime also appears to breach the equivalence of care principle. The National Health Committee identified the equivalence of care principle requires "all prisoners [to] be able to access the same level of healthcare and disability support services as the public outside prison who have the same level of need". ${ }^{261}$ This is manifestly not the case for ABI prisoners. The treatment services needed to rehabilitate ABI-related executive dysfunction are "highly specialised" and require a dedicated therapeutic environment. ${ }^{262}$ Despite this, there are no secure ABI rehabilitation facilities for prisoners with executive dysfunction to receive such treatment. $^{263}$ As a consequence, serious offenders with ABI must remain in prison. This is not best practice. $\mathrm{ABI}$ rehabilitation has been identified as optimally provided in a specialist residential facility where the patient can be managed by specialist health practitioners, not custodial staff. ${ }^{264}$ Custodial staff are not health trained, operate under a different professional philosophy, and may not be sensitive to the needs of an ABI rehabilitation programme. ${ }^{265}$

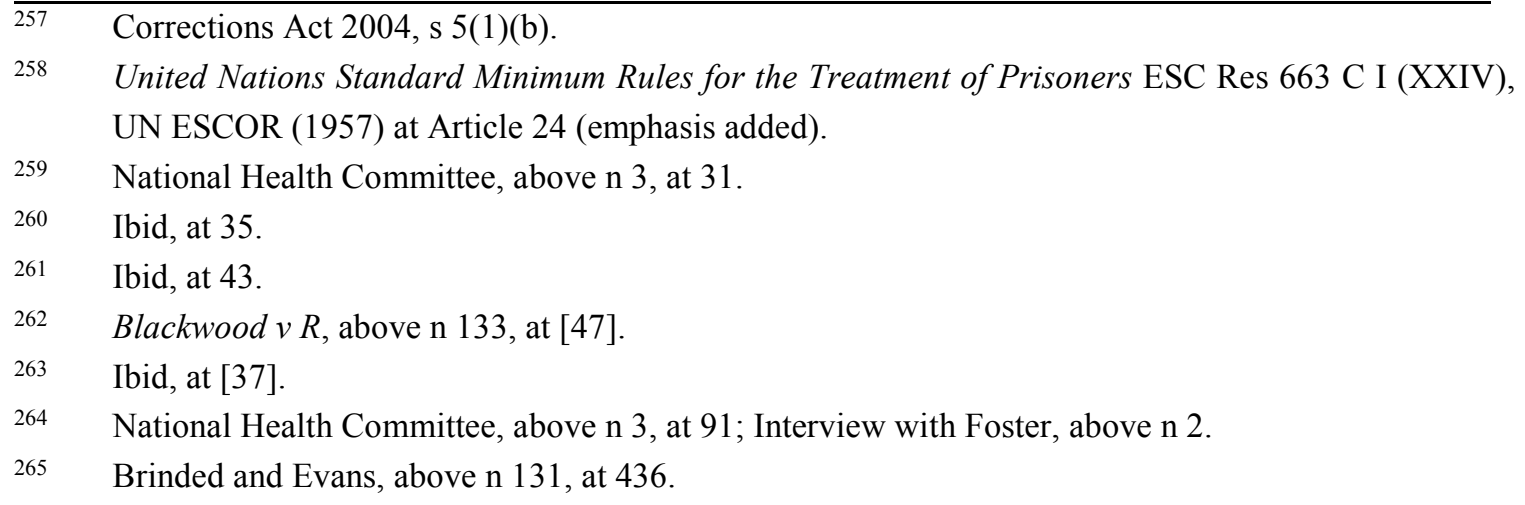


In contrast to the treatment services available to prisoners, non-prisoners have need-based access to specialist ABI rehabilitation programmes funded through the Accident Compensation Corporation or the Ministry of Health. ${ }^{266}$ This includes residential care and individualised rehabilitation with neurorehabilitation, occupational therapy, physiotherapy, psychological treatment, pharmaceutical treatment, speech therapy or other forms of ABI-related treatment. ${ }^{267}$ As prisoners are not currently able to be placed in such specialist ABI rehabilitation programmes, even if they present with serious brain injury like Mr Blackwood, the equivalence of care principle is not satisfied. The standard of care available to prisoners is significantly lower than the standard available to nonprisoners.

It could also be argued that a more nuanced assessment of the equivalence of care principle would emphasise it is limited by "reasonableness". Section 75(2) of the Corrections Act 2004 states "the standard of health care that is available to prisoners ... must be reasonably equivalent to the standard of health care available to the public". Accordingly, the fact a prisoner with ABI is not provided dedicated residential therapy when a non-prisoner is may not breach the equivalence principle alone. Provided such a prisoner received access to adequate $\mathrm{ABI}$ rehabilitation in prison, the obligation may be satisfied.

However, even on this more nuanced view, the equivalence principle appears violated by the status quo. There are currently no in-prison ABI rehabilitation programmes, ${ }^{268}$ and $\mathrm{ABI}$ treatment providers are not known to be contracted into prisons to provide services. $^{269}$ Accordingly, it appears that prisoners with ABI-related executive dysfunction currently receive no treatment or care services. This violates prisoners' right to treatment and the equivalence of care principle: the total absence of specialist treatment is not reasonably equivalent to the standard of care available to a member of the

\footnotetext{
$266 \quad$ Interview with Foster, above $\mathrm{n} 2$.

267 Ibid.

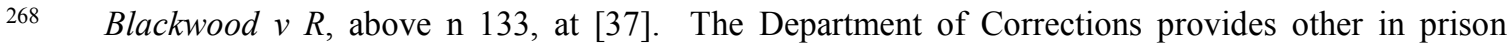
treatment services including alcohol and drug rehabilitation and psychological services and offers some dedicated residential units for prisoners on these programmes. However, such support services do not extend to $\mathrm{ABI}$ issues or any other form of cognitive or neurological deficit. See Department of Corrections "Working with Offenders: Rehabilitation Programmes" $<$ www.corrections.govt.nz $>$.

269 Interview with Foster, above n 2.
} 
public with the same health needs. As such, secure therapeutic facilities for ABI rehabilitation need to be established to ensure the state meets its statutory obligations.

The scope of the right to treatment and equivalence principle are untested in the New Zealand courts and so the exact standard required is unclear. This is likely a result of the bar on personal injury litigation in the Accident Compensation regime. ${ }^{270}$ If the very high standard required for exemplary damages cannot be established, a prisoner is not entitled to directly claim for a breach of these provisions as the Accident Compensation regime automatically covers any physical harm suffered as a consequence. ${ }^{271}$

\section{B Ill treatment as a consequence of imprisonment}

Not only does imprisoning ABI offenders without providing rehabilitation violate the statutory right to treatment, it may also violate the NZBORA on the grounds of ill treatment.

\section{The right to be free from ill treatment}

The NZBORA prohibits ill treatment in ss 9 and 23(5). Section 9 is a negative right: it absolutely prohibits state activity amounting to torture or cruel, degrading, or disproportionately severe treatment or punishment. ${ }^{272}$ Section 23(5) is a positive right: it requires the state to ensure all persons who it deprives of liberty are treated with "humanity and with respect for the inherent dignity of the person". ${ }^{273}$ The two rights were identified by the Supreme Court as forming a hierarchy. ${ }^{274}$ Section 9 covers more reprehensible conduct, to be "utterly condemned as outrageous and unacceptable in any circumstances", ${ }^{275}$ while s $23(5)$ covers conduct "of a lesser order, not rising to a level deserving to be called outrageous" but which is still unacceptable. ${ }^{276}$

Section 9 has a narrow scope. It is reserved for "truly egregious cases which call for a level of denunciation of the same order as that appropriate for torture". ${ }^{277}$ Establishing a

\footnotetext{
$270 \quad$ See Accident Compensation Act 2001, s 317(1).

$271 \quad$ Harris $v$ Attorney-General (2004) 7 HRNZ 369 (HC).

272 New Zealand Bill of Rights Act 1990, s 9.

273 Ibid, s 23(5).

274 Taunoa v Attorney General [2007] NZSC 70, [2008] 1 NZLR 429 at [339].

275 Ibid, at [170].

276 Ibid

277 Ibid, at [297].
} 
breach of the right requires a "high threshold to be met". ${ }^{278}$ This has been strictly applied in recent case law with s 9 found not to have been breached despite manifestly improper treatment of persons detained in state custody. Two examples illustrate this. First, in Falwasser, a mentally ill criminal suspect was struck on the head with a baton and pepper sprayed for some 20 minutes through the vents of an enclosed police cell, causing him significant physical and psychological distress. ${ }^{279}$ This conduct was found not to reach the level required for a violation of s $9,{ }^{280}$ despite it being deliberate, excessive, ${ }^{281}$ and causing ongoing harm in the form of post traumatic stress disorder. ${ }^{282}$ Second, in Taunoa, the right was found not violated by prison staff implementing a "behaviour modification regime" that involved keeping prisoners in solitary confinement for up to 23 hours per day with minimal access to physical exercise or natural light, in the worst case lasting for nearly three years. ${ }^{283}$ Thus, it will take an extraordinary and rare case to establish a violation of s 9 under current New Zealand law.

Section 23(5) has a much wider scope and contains a lower threshold to establish a breach. Section 23(5) has been identified as covering conduct that "lacks humanity, but falls short of cruelty", that is "demeaning but not degrading", and that is "clearly excessive in the circumstances but not grossly so". ${ }^{284}$ The demeaning and excessive treatment of the detained persons in both Falwasser and Taunoa violated s 23(5).

In addition to demeaning or excessive treatment, s 23(5) can also be violated by the state failing to adhere to minimum requirements for the treatment of prisoners as contained in domestic legislation (principally the Corrections Act 2004) or in the United Nations Standard Minimum Rules for the Treatment of Prisoners ("UN Standards"), collectively referred to as "the standards" herein. ${ }^{285}$ A breach of the standards will not automatically violate $\mathrm{s} 23(5),{ }^{286}$ but as they provide an indication of what is acceptable and

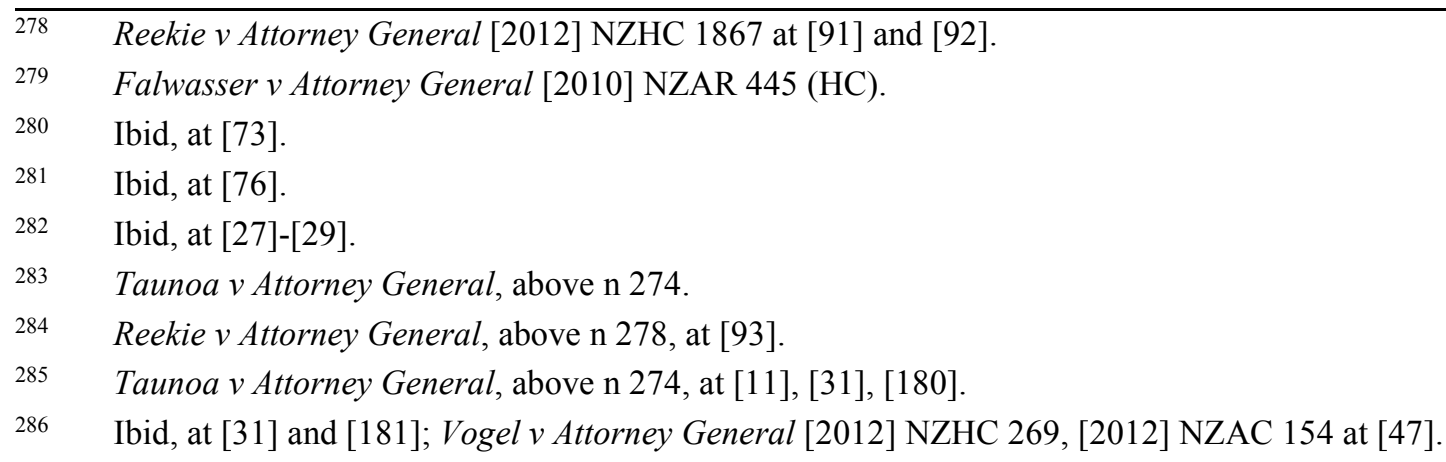


unacceptable treatment of prisoners, ${ }^{287}$ non-compliance "bears very heavily indeed on assessment of breach".288

\section{Does imprisoning an offender with ABI amount to ill treatment?}

Imprisoning an offender with $\mathrm{ABI}$ without provision for their needs may violate the right to be free from ill treatment on two grounds. First, the heightened vulnerability of people with $\mathrm{ABI}$ may render their imprisonment unduly harsh, violating ss 9 or 23(5). Second, as prisoners do not receive ABI treatment while in prison there is an arguable breach of the standards, violating s 23(5). These arguments are explored below.

(a) Unduly harsh experience of prison

The prison environment may be more severe for a person with ABI than for a nonimpaired person, potentially rendering their imprisonment within the realm of ill treatment. This is illustrated by three characteristics of ABI prisoners: vulnerability; heightened propensity to be placed in an at-risk unit; and heightened propensity to be subject to prison discipline. First, prisoners with ABI are often vulnerable to being victimised by other prisoners through physical or sexual assault, intimidation or bullying. ${ }^{289}$ Such vulnerability is often a result of the adverse effects of executive dysfunction on gauging socially appropriate behaviour and managing aggression or impulsivity. ${ }^{290}$

This was manifest in Blackwood $v R$. Expert evidence identified Mr Blackwood's executive dysfunction would make him vulnerable to exploitation and place him at risk from other inmates. ${ }^{291}$ In its decision, the Court of Appeal identified that as he had already been in a number of prison fights, "the fears as to how Mr Blackwood might fare in the custodial setting have been realised". ${ }^{292}$ Consequently, he was placed in an at-risk unit to ensure his safety. ${ }^{293}$ Such a demonstrably increased likelihood of experiencing violence and intimidation may render imprisonment a harsher experience for ABI

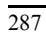

Taunoa v Attorney General, above n 274, at [11]; Reekie v Attorney General, above n 278, at [94].

Taunoa v Attorney General, above n 274, at [31].

Brown and Kelly, above n 236, at [6.3]; Interview with Foster, above n 2; Interview with Hansen, above n 2; Interview with McWaine, above n 201.

Brown and Kelly, above n 236, at [6.3]; Interview with Hansen, above n 2.

Blackwood $v R$, above n 133, at [47]-[49].

Ibid, at [36].

Ibid, at [41] and [fn 14]. 
prisoners than other prisoners. This may mean it is excessive or disproportionate, breaching ss 9 and 23(5) of the NZBORA.

Supporting this analysis, in a pre-ID(CCR)Act decision, $R v P$, the High Court held that sentencing a moderately intellectually disabled sexual offender to imprisonment would constitute cruel or disproportionately severe punishment, breaching s 9 NZBORA. ${ }^{294}$ Williams J considered expert evidence that identified the offender was "plainly vulnerable" due to his mental impairment and "might be subject to sexual attacks if imprisoned", rendering him likely to become "fearful and suicidal". ${ }^{295}$ This risk meant his imprisonment would be "inappropriate, disproportionate and unsuitable".296 Accordingly, the offender, who, if unimpaired, would have received a significant term of imprisonment, received a community sentence. ${ }^{297}$

Given the extremely high threshold set in more recent case law on s 9 NZBORA, it is unclear whether the $R v P$ fact pattern would still violate the right. Despite this, the case provides a useful example of how a mentally impaired person's heightened vulnerability may render their (otherwise justified) imprisonment excessive or disproportionate. Further, as excessive treatment is also grounds for a violation of s 23(5) NZBORA, ${ }^{298}$ this may support a claim that incarcerating a mentally impaired person identified as at high risk of victimisation (such as Mr Blackwood) may constitute ill treatment under that wider right.

A second and related characteristic of $\mathrm{ABI}$ offenders that may render imprisonment unduly harsh is the likelihood of placement in an at-risk unit. This may result from increased victimisation, as occurred with $\mathrm{Mr}$ Blackwood. It can also result from a prisoner with ABI being aggressive or victimising others, ${ }^{299}$ resulting in placement in the unit to minimise the risk to others. ${ }^{300}$ Alternatively, it may result from the propensity of ABI prisoners to become suicidal or attempt to self harm. Research in Australia identified inmates with TBI exhibit much higher rates of self harm than inmates without TBI. ${ }^{301}$ In addition, inmates with TBI are three to four times more likely to suicide. ${ }^{302}$

\footnotetext{
$294 \quad R v P(1993) 10$ CRNZ 250 (HC) (unpaginated).

$295 \quad$ Ibid.

296 Ibid.

297 Ibid.

298 Reekie v Attorney General, above n 278, at [93].

299 Interview with McWaine, above n 201.

300 National Health Committee, above n 3, at 35.

301 Brown and Kelly, above n 236, at [6.5].
} 
Consequently, prisoners with $\mathrm{ABI}$ are much more likely to be placed in at-risk units than non-ABI prisoners.

Placement in at-risk units has been identified as punitive and risks exacerbating the harshness of the prison environment for a person with $\mathrm{ABI} .{ }^{303}$ At-risk units are prison wings where prisoners are kept in isolation and continuously observed by prison staff. ${ }^{304}$ The isolation cells are small and bare, lack fresh air, and result in very limited social contact for the prisoner. ${ }^{305}$ Consequently, placement in these units is seen by inmates as a form of punishment. ${ }^{306}$ In addition, for prisoners with cognitive disability (including $\mathrm{ABI})$ the units can cause deterioration in physical and mental health, largely a result of the adverse effects of segregation and isolation on brain function. ${ }^{307}$ As such, the use of at-risk units to mitigate an ABI prisoner's susceptibility to maltreatment, or to manage aggressive or self-harming behaviour, may exacerbate the potential for incarceration to be excessive or disproportionate and therefore breach ss 9 or 23(5) NZBORA.

The third characteristic of an ABI prisoner that may render imprisonment unduly harsh is their reduced ability to understand and follow prison rules. ${ }^{308}$ As discussed in Part III, ABI-related executive dysfunction can impede a person's ability to process information, remember rules, and use memory to foresee the consequences of behaviour. ${ }^{309}$ Therefore, $\mathrm{ABI}$ inmates are more likely to commit in-prison offences, be subject to disciplinary hearings, and receive in-prison punishments such as loss of privileges, isolation, or extended sentences. ${ }^{310}$ The increased likelihood of ABI prisoners to commit in-prison offences and receive additional punishments as a result of their disability also supports an argument that imprisoning such persons may be excessive and violate the right to be free from ill treatment.

Ibid.

Parliament of Victoria Law Reform Committee, above n 25, at 315; National Health Committee, above $\mathrm{n} 3$, at 35 .

National Health Committee, above n 3, at 35.

Ibid.

Ibid.

Parliament of Victoria Law Reform Committee, above n 25, at 315; Brown and Kelly, above n 236, at [6.5].

Brown and Kelly, above n 236, at [6.3].

Aharon-Peretz and Tomer, above n 1, at 541 and 544; Cavit and Foster, above n 1; Lavelle and Barker-Collo, above n 14, at 220.

Brown and Kelly, above n 236, at [6.3]. 
(b) Breach of the standards

The second substantive ground of argument establishing ill treatment is the breach of standards. As discussed earlier, a breach of the standards may justify a finding of ill treatment depending on its nature and consequences. ${ }^{311}$ Three breaches of the standards could be argued here. First, as explored in subpart A above, a breach of the right to treatment in s 75 of the Corrections Act 2004. A second and related breach is of Article 62 of the UN Standards which requires prison medical services to detect and treat "any physical or mental illnesses or defects which may hamper a prisoner's rehabilitation".312 As ABI is clearly an impairment which may impede the potential for rehabilitation, the inadequate detection or treatment of it in the current prison system may breach Article 62 . Third, Article 82(2) of the UN Standards requires prisoners who suffer from "mental abnormalities" to be observed and treated in specialised institutions. ${ }^{313}$ Prisoners with $\mathrm{ABI}$ are currently detained in the general prison environment and not placed in specialist units or transferred into dedicated therapeutic facilities. ${ }^{314}$ Such failure to make any special provision for an identifiably high needs category of prisoner appears inconsistent with Article 82(2).

As such, it is arguable the current imprisonment of ABI offenders breaches a number of the standards. This supports the argument that such imprisonment is a prima facie breach of s 23(5) NZBORA. When coupled with the disproportionately harsh experience of imprisonment on an $\mathrm{ABI}$ inmate, the current practice of imprisoning $\mathrm{ABI}$ offenders may violate their human rights. Accordingly, there is a need to expand the court's therapeutic jurisdiction to divert $\mathrm{ABI}$ offenders from prison and into treatment. Without such provision, the continued incarceration of $\mathrm{ABI}$ offenders could be challenged and the state found liable for breaching its human rights obligations.

\section{An analogy with intellectual disability}

The argument to expand the therapeutic regime is supported by the ID(CCR)Act's history, which evidences a striking similarity between the previous position of intellectually disabled offenders and the current position of ABI offenders. Accordingly,

$311 \quad$ Taunoa v Attorney General, above n 274, at [31] and [296].

312 United Nations Standard Minimum Rules for the Treatment of Prisoners ESC Res 663 C I (XXIV), UN ESCOR (1957), Article 62.

313 Ibid, Article 82(2).

$314 \quad$ National Health Committee, above n 3, at 89. 
just as the then untenable position of intellectually disabled offenders justified an expansion of the court's therapeutic jurisdiction to divert such people into care, the analogous position of $\mathrm{ABI}$ offenders in the contemporary regime justifies a similar expansion.

\section{A brief history of the $I D(C C R) A c t$}

The ID(CCR)Act was enacted to remedy an injustice created by excluding intellectually disabled offenders from the court's therapeutic jurisdiction under the MH(CAT)Act. ${ }^{315}$ Prior to the enactment of the $\mathrm{MH}(\mathrm{CAT})$ Act, intellectually disabled persons were captured by the definition of mental disorder in the Mental Health Act 1969 which allowed intellectually disabled persons to be detained under compulsory treatment orders and also gave the court jurisdiction to grant therapeutic dispositions for intellectually disabled offenders via the Criminal Justice Act 1985. ${ }^{316}$ While this ensured intellectually disabled offenders were not inappropriately imprisoned, it meant they were treated as if mentally ill and detained in psychiatric facilities. ${ }^{317}$ As medical knowledge of intellectually disability developed, this was perceived as inappropriate: intellectually disabled persons had an identifiably different type of impairment and very different health needs than the mentally ill. ${ }^{318}$ Consequently, when the MH(CAT)Act was enacted to replace the Mental Health Act 1969, the legislative drafters deliberately excluded intellectual disability from the definition of mental disorder to prevent the exercise of its powers in respect of the intellectually disabled. ${ }^{319}$

An unforeseen consequence of the exclusion of intellectual disability from the $\mathrm{MH}(\mathrm{CAT})$ Act was the loss of the court's jurisdiction to order therapeutic dispositions for intellectually disabled offenders at sentencing. ${ }^{320}$ This created a "legislative gap" which resulted in intellectually disabled offenders being inappropriately imprisoned (and therefore at risk of maltreatment) $)^{321}$ or released into the community without their

\footnotetext{
$315 \quad$ Intellectual Disability (Compulsory Care) Bill 1999 (329-1) (explanatory note) at ii.

316 Ibid.

317 Bell and Brookbanks, above n 132, at 58.

318 Intellectual Disability (Compulsory Care) Bill 1999 (329-1) (explanatory note) at ii; Bell and Brookbanks, above n 132, at 58. Mental Health (Compulsory Assessment and Treatment) Act 1992, s 4(e).

Webb, Duff and Reed, above n 98, at 206.

Parliament of Victoria Law Reform Committee, above n 25, at 315.
} 
offending behaviour being addressed or the risk they posed to others managed. ${ }^{322}$ Accordingly, the exclusion of intellectually disabled offenders from therapeutic dispositions was rightly perceived as creating an injustice, leaving such persons not "adequately protected in criminal justice proceedings". 323

Concern over this legislative gap led to the development of the ID(CCR)Act which established a sui generis regime for intellectually disabled offenders. This ensures such persons receive specialised care in dedicated facilities rather than being inappropriately detained in prison or psychiatric institutions. ${ }^{324}$ The ID(CCR)Act regime is identified as reflecting "well-established international thinking" about the care needs of intellectually disabled offenders, ${ }^{325}$ and as resulting in "many beneficial clinical outcomes" through providing offenders access to specialised rehabilitation programmes that reduce recidivism and address the previously unmet social and health needs of this group. ${ }^{326}$

\section{A similar path: what the ID(CCR)Act's history shows about ABI offenders}

There are some interesting similarities between the pre-ID(CCR)Act position of intellectually disabled offenders and the current position of $\mathrm{ABI}$ offenders. First, as occurred with intellectually disabled offenders, the exclusion of ABI offenders from therapeutic dispositions creates a "legislative gap" meaning such persons are imprisoned despite their vulnerability to harm and lesser ability to understand or be reformed by the experience of punishment. ${ }^{327}$ Such inappropriate imprisonment of intellectually disabled offenders was identified as an injustice requiring reform. ${ }^{328}$ Surely this is apposite to the current imprisonment of $\mathrm{ABI}$ offenders who today stand in the same position as the intellectually disabled did pre-ID(CCR)Act. Second, just as the healthcare needs of the intellectually disabled are different to those of the mentally ill, the needs of persons with ABI also differ to these two categories. ${ }^{329}$ Detaining intellectually disabled persons in mental health facilities was identified as inappropriate given their different conditions,

\footnotetext{
322 Intellectual Disability (Compulsory Care) Bill 1999 (329-1) (explanatory note) at ii; Webb, Duff and Reed, above n 98, at 206.

323 Visser, above n 82, at 193.

324 Webb, Duff and Reed, above n 98, at 210.

325 Bell and Brookbanks, above n 132, at 66.

326 Webb, Duff and Reed, above n 98, at 210.

327 See Blackwood $v$ R, above $\mathrm{n} 133$.

328 Intellectual Disability (Compulsory Care) Bill 1999 (329-1) (explanatory note) at ii.

329 Interview with Hansen, above n 2; Interview with Foster, above n 2.
} 
and therefore a sui generis regime was necessary. ${ }^{330}$ As people with ABI also have a different form of mental impairment than the mentally ill and the intellectually disabled and require different care and treatment, ${ }^{331}$ the justification for a need-specific therapeutic regime surely extends to them.

Given these similarities, and the positive outcomes that have resulted from the $\mathrm{ID}(\mathrm{CCR})$ Act regime, the current position of $\mathrm{ABI}$ offenders seems unprincipled. The ID(CCR)Act's legislative history suggests that where a cohort of criminal offenders labour under an identifiable mental impairment that would benefit from treatment or rehabilitation, and which renders their imprisonment unjust and detention in other therapeutic facilities inappropriate, consideration should be given to a unique therapeutic regime. This applies to $\mathrm{ABI}$ offenders. Without the development of therapeutic facilities to cater for their need, ABI offenders, like the intellectually disabled before them, will not be "adequately protected in criminal justice proceedings". 332 Excluded from the therapeutic jurisdiction, they will continue to endure maltreatment in prison and be released back into the community without the risk posed by their mental impairment being addressed.

\section{Addressing the Inequity: How to Better Provide for ABI Offenders}

This paper has argued the current exclusion of ABI offenders from the court's therapeutic jurisdiction is unjustifiable as it places the state in breach of its statutory duties and is unprincipled. Accordingly, better provision needs to be made for ABI offenders. This section explores two options for doing so.

\section{A In-prison rehabilitation programmes}

First, in-prison rehabilitation programmes could be established to ensure appropriate healthcare services are provided to prisoners with ABI. A comparative model is found in Victoria (Australia) where two in-prison programmes provide treatment and support for violent or sexual ABI offenders ineligible for therapeutic diversions. ${ }^{333}$ Through the

\footnotetext{
$330 \quad$ Intellectual Disability (Compulsory Care) Bill 1999 (329-1) (explanatory note) at ii.

331 See Parliament of Victoria Law Reform Committee, above n 25, at 40-41; Interview with Hansen, above $\mathrm{n} 2$.

332 Visser, above n 82, at 193.

333 In Victoria, therapeutic dispositions (known as hospital security orders) are only available to offenders with mental illness: Department of Health, State Government of Victoria, Australia "Sentencing and Mental Health Acts (Amendment) Act 2005: Summary of Key Amendments"
} 
"Corrections Victoria ABI Program", specialist clinical consultants work with prisons to identify, assess, and manage ABI prisoners. ${ }^{334}$ Once ABI is identified, an individual treatment plan is developed and "early and direct specialist interventions" provided to address ABI-related adverse behaviour. ${ }^{335}$ The programme has been identified as improving outcomes for ABI offenders. ${ }^{336}$

A second programme is the "Disability Prison Pathways Program" which caters for all forms of cognitive impairment, including $\mathrm{ABI} .{ }^{337}$ In this programme, cognitively impaired inmates are placed in specialist units away from the general prison population. ABI offenders are placed in a specific unit in Port Phillip Prison, to which they are referred on sentencing, or presumably transferred if their ABI is identified after admission to prison. ${ }^{338}$ The unit employs a therapeutic approach. ${ }^{339}$ Prisoners are needsassessed and placed on individualised programmes to address their particular cognitive deficits, and any violence, sexual, or substance abuse issues. 340 "Positive improvements" have been recorded since the programme's implementation, particularly in reduced recidivism. ${ }^{341}$

Given these benefits, the introduction of similar programmes in New Zealand should be considered. This would address some of the legal problems of our current system, as inprison identification, and the creation of a specialist unit to provide $\mathrm{ABI}$ rehabilitation to consenting inmates, would better realise prisoners' right to treatment.

However, practitioners interviewed for this research expressed mixed views on the propriety of in-prison treatment. Two practitioners considered in-prison ABI rehabilitation should be a last resort, given the harshness of the prison environment and

(2006) < www.health.vic.gov.au>. Other mentally impaired offenders, including those with ABI, are eligible for therapeutic diversion through problem solving courts. However, serious violent or sexual offenders are ineligible for such programmes, so it is not an appropriate model for the category of offenders addressed here: Parliament of Victoria Law Reform Committee, above n 25, at 250 and 252.

Brown and Kelly, above n 236, at [6.8.2].

Ibid.

Ibid.

Ibid, at [6.8.4].

Ibid, at [6.8.7].

Ibid.

Ibid.

Ibid. 
the lack of health training of custodial staff. ${ }^{342}$ Only if staff were properly trained, the programme properly resourced, and the unit segregated, would this option be acceptable. ${ }^{343}$ However, another practitioner noted that where an ABI offender is violent or poses a risk of harm to others (as is often the case for the category of offenders addressed in this paper) in-prison treatment programmes may be necessary. ${ }^{344}$ Prison staff have particular expertise in managing violent and other dangerous behaviours and so only once risk is reduced to an acceptable level should an impaired offender be transferred out of the corrections jurisdiction and into an alternative facility. ${ }^{345}$

\section{B Secure ABI rehabilitation facilities outside prison}

A second reform option is to establish a dedicated ABI rehabilitation facility outside prison. Such a facility would need to cater for the security, as well as therapeutic, needs of ABI offenders to address the legitimate public safety concerns identified above. However, the forensic mental health units and intellectual disability care facilities that currently operate accept serious violent and sexual offenders and so are appropriate models to base an ABI rehabilitation centre upon. These facilities operate under the jurisdiction of the Ministry of Health and are therapeutic in focus, but have security measures to restrict patients' movements and ensure custodial requirements are also met. $^{346}$

The establishment of a secure ABI rehabilitation facility outside prison would also reflect best practice healthcare for offenders and so is preferred to in-prison therapy. This is largely due to differences in institutional design and competence. Prisons are not therapeutic in design or practice. Prison buildings are often basic and lack the equipment and facilities available in purpose-built therapeutic settings. ${ }^{347}$ The prison environment and routine is designed for custody, not therapy. ${ }^{348}$ Adequate monitoring of inmates' health and condition may not be possible with prison lock-down periods, ${ }^{349}$ and ABIspecific care, such as fatigue management, may not be conducive to rigid prison

\footnotetext{
Interview with Hansen, above n 2; Interview with Foster, above n 2.

343 Ibid.

$344 \quad$ Interview with McWaine, above n 201.

345 Ibid.

346 Sandy Simpson "New Zealand Provision of Forensic Mental Health Services" (2008) Rethinking Crime and Punishment (2008) <www.rethinking.org.nz $>$.

347 Brinded and Evans, above n 131, at 423, 431 and 436.

348 National Health Committee, above n 3, at 41.

$349 \quad$ Brinded and Evans, above n 131, at 431.
} 
timetables. $^{350}$ Prison staff are also mostly custodial. They are not trained in healthcare and may lack the necessary knowledge and philosophical orientation to provide high level therapeutic care. ${ }^{351}$ As noted by Brinded and Evans, "prison officers deal with prisoners" whereas health professionals "maintain interactions with patients". 352 Finally, there is a recognised tension between the institutional goals of the corrections' system and those of the health system. ${ }^{353}$ This conflict justified the transfer of responsibility for mentally ill offenders to the health jurisdiction, ${ }^{354}$ and seems apposite to ABI offenders. Therapeutic services are best provided by the health sector and ABI rehabilitation is a therapeutic service.

Accordingly, ABI rehabilitation for offenders should be provided in specialist facilities run under the Ministry of Health's jurisdiction and not as in-prison programmes. If this was accepted and $\mathrm{ABI}$ rehabilitation provided outside prison, a legal mechanism would be needed to transfer the offender out of the corrections jurisdiction and into the health jurisdiction. Two options for this are explored below.

\section{Expanding the mental disorder definition under the MH(CAT)Act}

An obvious mechanism to transfer an ABI offender into the new therapeutic facility is the current $\mathrm{MH}(\mathrm{CAT})$ Act regime. As discussed above, where "mentally disordered" and in need of compulsory treatment, an offender can be diverted from prison and into the $\mathrm{MH}(\mathrm{CAT})$ Act regime. ${ }^{355}$ This was identified as only appropriate for offenders for whom "treatment" is available in the relevant certified hospitals or its risks being unlawful. Accordingly, an additional requirement of "treatability" was proposed as part of the "mental disorder" definition. However, if ABI rehabilitation facilities were established and certified, ${ }^{356}$ proper treatment of the mental disorder would be available under the $\mathrm{MH}(\mathrm{CAT}) \mathrm{Act}$, and the current restriction on the definition applying to ABI offenders would fall away. Thus, provided the offender met the other requirements of the definition, the $\mathrm{MH}(\mathrm{CAT})$ Act could be a conduit to the new therapeutic facility.

\footnotetext{
$350 \quad$ Interview with Foster, above $\mathrm{n} 2$.

351 National Health Committee, above n 3, at 41.

352 Brinded and Evans, above n 131, at 436.

353 National Health Committee, above n 3, at 41; Brinded and Evans, above n 131, at 436.

$354 \quad$ Brinded and Evans, above n 131, at 424.

355 Criminal Procedure (Mentally Impaired Persons) Act 2003, ss 34(2) and (3).

356 The facility would need to be certified as a relevant "hospital" by the Director-General of Health: Mental Health (Compulsory Assessment and Treatment) Act 1992, s 2(1) and Health and Disability Services (Safety) Act 2001, s 9.
} 
Using the existing "mental disorder" definition as a gateway to the expanded therapeutic regime offers several advantages. First, the definition is broad. This reduces the risk of an overly-prescriptive definition creating arbitrariness as to who is included, and excluded, from the therapeutic jurisdiction. This was seen in $R v$ Satherley where the ID(CCR)Act's prescriptive definition excluded an otherwise eligible offender, potentially creating injustice. ${ }^{357}$ With a broad definition, each offender's case can be considered on its merits, with the relevant health assessors identifying whether or not that offender requires treatment. Second, no legislative change would be required. Once the DirectorGeneral had certified the secure ABI rehabilitation facility a "hospital" for the purposes of the $\mathrm{MH}(\mathrm{CAT})$ Act, the statutory regime would automatically encompass it. This would be time and resource efficient. In addition, the $\mathrm{MH}(\mathrm{CAT})$ Act provides a comprehensive supervisory regime to protect those subject to it, and ABI offenders would benefit from this.

\section{Enactment of an ABI specific statute}

Alternatively, a sui generis statute could be enacted. This would have some advantages over incorporating $\mathrm{ABI}$ into the $\mathrm{MH}(\mathrm{CAT})$ Act regime. First, and conversely to the above, a specific threshold definition could be introduced. Some offenders may seek to use their ABI to avoid taking responsibility for their offending, ${ }^{358}$ which would be easier under a broad definition like "mental disorder". An ABI-specific definition could more tightly prescribe the severity of executive dysfunction needed to warrant a therapeutic disposition and so ensure all offenders diverted into the therapeutic regime would genuinely benefit from it.

Second, a separate legislative regime would have greater conceptual clarity. Just as intellectual disability and mental illness are recognised as different forms of mental impairment that should not be managed under one framework, ${ }^{359}$ ABI may deserve a unique rubric. ABI has different symptoms and therapeutic needs to the mental illnesses typically captured within the $\mathrm{MH}(\mathrm{CAT})$ Act regime. ${ }^{360}$ Grouping multiple categories of mental impairment under one statute may fail to accommodate the particular needs and

\footnotetext{
$357 \quad R v$ Satherley, above $\mathrm{n} 77$.

$358 \quad$ Interview with McWaine, above $\mathrm{n} 201$.

359 Intellectual Disability (Compulsory Care) Bill 1999 (329-1) (explanatory note) at ii.

360 Interview with Hansen, above n 2; Interview with Foster, above n 2.
} 
issues of each category, ${ }^{361}$ and so may not be best practice. Accordingly, while this paper lacks the scope to consider what an ABI-specific statute should contain, there is some logic in developing separate legislation.

In summary, there are advantages in both legislative mechanisms. However, on the basis that careful drafting could avoid an over-prescriptive definition and avoid the rigidity of the $\mathrm{ID}(\mathrm{CCR})$ Act's gateway definition, a sui generis statute is preferable. It seems logical to have different legislative regimes for broadly different forms of mental impairment, as the ID(CCR)Act is itself precedent for.

\section{Conclusion}

This paper analysed the legislative framework for diverting mentally impaired offenders from prison and into therapeutic services. It demonstrated how this framework currently excludes ABI offenders as a result of the gateway definitions of "intellectual disability" and "mental disorder". This exclusion is untenable as it means serious offenders with $\mathrm{ABI}$ are imprisoned where their health condition is untreated and they are at risk of maltreatment. Accordingly, the status quo may violate human rights law and domestic legislation prescribing minimum standards for the treatment of prisoners.

To remedy this, the paper recommended secure ABI rehabilitation facilities be established under the jurisdiction of the Ministry of Health and an ABI-specific statute be enacted to facilitate diversion into this new regime. An expanded therapeutic regime would better realise the state's obligations and would also better protect the public. The current legislative framework fails to address the underlying causes of offending behaviour in persons with $\mathrm{ABI}$ and so does little to reduce recidivism. Rather than continue to cycle ABI offenders through the criminal justice system, the law needs to reflect developing medical knowledge of criminality in persons with $\mathrm{ABI}$ and work to facilitate their rehabilitation.

$361 \quad$ Interview with McWaine, above n 201 


\section{Bibliography}

\section{A Legislation}

Accident Compensation Act 2001.

Corrections Act 2004.

Criminal Procedure (Mentally Impaired Persons) Act 2003.

Health and Disability Services (Safety) Act 2001.

Intellectual Disability (Compulsory Care and Rehabilitation) Act 2003.

Mental Health (Compulsory Assessment and Treatment) Act 1992.

New Zealand Bill of Rights Act 1990.

Sentencing Act 2002.

\section{B Parliamentary Materials}

Criminal Justice Amendment Bill (No 7) 1999 (328-2) (select committee report).

Intellectual Disability (Compulsory Care) Bill 1999 (329-1) (explanatory note).

Intellectual Disability (Compulsory Care) Bill 1999 (329-2) (select committee report).

\section{Case Law}

Blackwood v R [2011] NZCA 143.

Byford v R [2011] NZCA 116.

Canterbury District Health Board v MH [2012] NZFC 4432, [2013] NZFLR 312.

Falwasser v Attorney General [2010] NZAR 445 (HC).

Harris v Attorney General (2004) 7 HRNZ 369 (HC).

Re $D G$ [2003] NZFLR 87 (MHRT).

Re JAB MHRT 07/20 (20 March 2007).

Ministry of Health v M FC Manukau FAM-2006-092-2802, 21 December 2006.

$R v$ Goodlet [2011] NZCA 357, [2011] 3 NZLR 783.

$R v P$ (1993) 10 CRNZ 250 (HC).

$R v$ Roberts [2012] NZHC 1384.

$R v$ Satherley [2007] NZCA 381, (2005) 25 FRNZ 709.

$R v$ Simmonds HC Christchurch CRI-2010-009-000716, 11 November 2010.

Re C MHRT08/057 (26 May 2008).

Reekie v Attorney General [2012] NZHC 1867. 
Taunoa v Attorney General [2007] NZSC 70, [2008] 1 NZLR 429.

Vaihu v Attorney General [2007] NZCA 574, (2007) 8 HRNZ 403.

Vogel v Attorney General [2012] NZHC 269, [2012] NZAC 154.

Waitemata District Health Board v B (2005) 25 FRNZ 709 (DC).

Waitemata Health v Attorney General [2001] NZFLR 1122 (CA).

\section{International Materials}

Body of Principles for the Protection of All Persons Under Any Form of Detention or Imprisonment GA Res 43/173, UN GOAR (1988).

United Nations Standard Minimum Rules for the Treatment of Prisoners ESC Res 663 CI (XXIV), UN ESCOR (1957).

\section{E Texts}

Andrew Ashworth Sentencing and Criminal Justice (5th ed, Cambridge University Press, Cambridge, 2010).

AP Simester and Warren Brookbanks Principles of Criminal Law (4th ed, Brookers, Wellington, 2012).

Sir Bruce Robertson (ed) Adams on Criminal Law (online looseleaf ed, Brookers).

Sylvia Bell (ed) Brookers Human Rights Law (online looseleaf ed, Brookers).

Sylvia Bell and Warren Brookbanks Mental Health Law in New Zealand (2nd ed, Brookers, Wellington, 2005).

Zainab Al-Alawi (ed) Brookers Family Law - Incapacity (online looseleaf ed, Brookers).

\section{F Essays in Texts}

Brian McKenna, Alexander Simpson and John Coverdale "Implementing Civil Commitment: Doing With Not Doing To" in Warren Brookbanks and Sandy Simpson (eds) Psychiatry and the Law (LexisNexis, Wellington, 2007) 69-100.

David Chaplow "Services for Mentally Abnormal Offenders: Some Important Issues" in Warren Brookbanks and Sandy Simpson (eds) Psychiatry and the Law (LexisNexis, Wellington, 2007) 383-396.

Elisa Lavelle and Suzanne Barker-Collo "Neuropsychology and the Assessment of Competence" in Fred Seymour, Suzanne Blackwell and John Thorburn (eds) Psychology and the Law in Aotearoa New Zealand (The New Zealand Psychological Society, Wellington, 2011) 215-234. 
James Ellis and Ruth Luckasson "Mentally Retarded Criminal Defendants" in Michael Perlin and Henry Dlugacz (eds) Mental Health Issues in Jails and Prisons (Caroline Academic Press, Durham, 2008) 162-171.

Jeremy Skipworth and Per Lindqvist "Rehabilitation in Forensic Psychiatry" in Warren Brookbanks and Sandy Simpson (eds) Psychiatry and the Law (LexisNexis, Wellington, 2007) 467-496.

Judith Aharon-Peretz and Rachel Tomer "Traumatic Brain Injury" in Bruce Miller and Jeffrey Cummings (eds) The Human Frontal Lobes: Functions and Disorders (2nd ed, The Guilford Press, New York, 2007) 540-551.

Mhairi Duff and Joseph Sakdalan "Intellectual Disabilities and the Law" in Warren Brookbanks and Sandy Simpson (eds) Psychiatry and the Law (LexisNexis, Wellington, 2007) 341-382.

Olive Webb, Mhairi Duff and Mike Reid “Assessment and Care of Offenders with Intellectual Disabilities" in Fred Seymour, Suzanne Blackwell and John Thorburn (eds) Psychology and the Law in Aotearoa New Zealand (The New Zealand Psychological Society, Wellington, 2011) 205-214.

Philip Brinded and Ceri Evans "Delivery of Mental Health Services in Prisons" in Warren Brookbanks and Sandy Simpson (eds) Psychiatry and the Law (LexisNexis, Wellington, 2007) 423-446.

Sabine Visser "Assessment and Care of Offenders with Mental Impairment" in Fred Seymour, Suzanne Blackwell and John Thorburn (eds) Psychology and the Law in Aotearoa New Zealand (The New Zealand Psychological Society, Wellington, 2011) 193-204.

Stephen Todd "Accident Compensation and the Common Law" in Stephen Todd (ed) The Law of Torts in New Zealand (6th ed, Thomson Reuters, Wellington, 2013) 21-72.

Stephen Todd “Accident Compensation in Operation" in Stephen Todd (ed) The Law of Torts in New Zealand (6th ed, Thomson Reuters, Wellington, 2013) 73-100.

Sylvia Bell "Defining Mental Disorder" in Warren Brookbanks and Sandy Simpson (eds) Psychiatry and the Law (LexisNexis, Wellington, 2007) 41-68.

Warren Brookbanks "Insanity" in Warren Brookbanks and Sandy Simpson (eds) Psychiatry and the Law (LexisNexis, Wellington, 2007) 123-156.

Warren Brookbanks "The Sentencing and Disposition of Mentally Disordered Offenders" in Warren Brookbanks and Sandy Simpson (eds) Psychiatry and the Law (LexisNexis, Wellington, 2007) 197-228. 


\section{G Journal Articles}

Drew Barzman and Manish Fozdar "Does Traumatic Brain Injury Cause Violence?" (2002) 1 The Journal of Family Practice (unpaginated online version) $<$ www.jfponline.com>.

Fred Cohen "Captives Legal Right to Mental Health Care" (1993) 17 Law and Psychology Review 1-39.

Jose Leon-Carrion and Francisco Javier Chacartegui Ramos "Blows to the Head During Development Can Predispose to Violent Criminal Behaviour: Rehabilitation of Consequences of Head Injury Is a Measure for Crime Prevention" (2003) 17 Brain Injury 207-216.

Nigel Dunlop "Compulsory Psychiatric Treatment and 'Mental Disorder"” [2006] NZLJ 225-232.

Oliver Lewis "Protecting the Rights of People with Mental Disabilities: The European Convention on Human Rights" (2002) 9 European Journal of Health Law 293-320.

Tracey Barnfield and Janet Leathem "Incidence and Outcomes of Traumatic Brain Injury and Substance Abuse in a New Zealand Prison Population" (1998) 12 Brain Injury 455466.

W Williams and others "Traumatic Brain Injury in a Prison Population: Prevalence and Risk for Re-Offending” (2010) 24 Brain Injury 1184-1188.

\section{H Government Publications}

Capital and Coast District Health Board Central Regional Forensic Mental Health Services: Draft 5 Year Development Plan (2007).

Department of Corrections "Working with Offenders: Rehabilitation Programmes" $<$ www.corrections.govt.nz $>$.

Department of Corrections Mental Health Screening Tool, Primary Mental Health Services and Packages of Care Policy and Procedure (Policy No 3-14, January 2013).

Department of Corrections Prison Health and Disability Support Service Specifications (2002).

Ministry of Health "Intellectual Disability (Compulsory Care and Rehabilitation) Act 2003" <www.health.govt.nz>.

Ministry of Health A Guide to the Intellectual Disability (Compulsory Care and Rehabilitation) Act 2003 (2004).

Ministry of Health Census of Forensic Mental Health Services 2005 (2007). 
Ministry of Health Guidelines to the Mental Health (Compulsory Assessment and Treatment) Act 1992 (2012).

National Health Committee Health in Justice Kia Piki te Ora, Kia Tika: Improving the Health of Prisoners and their Families and Whanau (Ministry of Health, 2010).

New Zealand Guidelines Group Traumatic Brain Injury: Diagnosis, Acute Management and Rehabilitation: Summary (Accident Compensation Corporation, 2007).

New Zealand Guidelines Group Traumatic Brain Injury: Diagnosis, Acute Management and Rehabilitation (Accident Compensation Corporation, 2006).

Office of the Auditor-General Performance Audit Report: Mental Health Services for Prisoners (2008).

Regional Public Health E Kore Koe e Ngaro: Opportunities to Improve Continuity of Primary Care for People Who Are, Or Have Been, Imprisoned Within the Greater Wellington Region (Hutt Valley District Health Board, 2012).

\section{Other Materials}

ABI Rehabilitation "Brain Injury Information”<www.abi-rehab.co.nz>.

Department of Health, State Government of Victoria "Sentencing and Mental Health Acts (Amendment) Act 2005: Summary of Key Amendments" (2006) $<$ www.health.vic.gov.au>.

Max Cavit and Allison Foster "Traumatic Brain Injuries Among Corrections Populations: Implications and Intervention Strategies" (2010) Rethinking Crime and Punishment $<$ www.rethinking.org.nz> (unpaginated).

Office of the Public Advocate Disability and the Courts - An Analysis of Problem Solving Courts and Existing Dispositional Options: The Search for Improved Methods of Processing Defendants with a Mental Impairment Through the Criminal Courts (2004).

Parliament of Victoria Law Reform Committee Inquiry into Access to and Interaction with the Justice System by People with an Intellectual Disability and their Families and Carers - Final Report (Parliamentary Paper No 216, 2013).

Sandy Simpson "New Zealand Provision of Forensic Mental Health Services" (2008) Rethinking Crime and Punishment $<$ www.rethinking.org.nz $>$.

Suzanne Brown and Glenn Kelly Issues and Inequities Facing People with Acquired Brain Injury in the Criminal Justice System (Victorian Coalition of ABI Service Providers Inc, 2012). 


\section{Word count}

The text of this paper (excluding table of contents, footnotes, and bibliography) comprises approximately 15,943 words. 


\section{Appendix One: Interview Questions}

1. What is your background / experience in identifying or treating mentally impaired persons who have committed criminal offences?

2. Do you think that there is a connection between traumatic brain injury and criminal offending?

a. If yes: can you explain what you think the connection is?

3. How do you see traumatic brain injury best characterised: an "intellectual disability"; a "mental disorder"; a "mental impairment"; or something different?

a. If "mental disorder": are you familiar with the definition of "mental disorder" in the $\mathrm{MH}(\mathrm{CAT}) \mathrm{Act}$ ?

b. If yes: can you explain how you see traumatic brain injury fulfilling its requirements?

4. Do you have any experience in working with people with traumatic brain injury who have committed criminal offences and, if so, in what context?

a. If yes: what is the usual outcome for such persons?

b. Do you see that as a similar or different outcome to offenders with a mental illness such as schizophrenia?

5. What is the potential for rehabilitation or treatment of brain injury? Could this be carried out in prison or does it necessitate removal to a treatment facility or hospital?

6. Is it appropriate to detain offenders with brain injury in the same facility as offenders with psychiatric illness (eg, in forensic mental health units)?

7. Are you familiar with the legislative framework for identifying and managing offenders with mental impairment (the MH(CAT)Act, ID(CCR)Act, and $\mathrm{CP}(\mathrm{MIP}) \mathrm{Act})$ ?

a. If yes: do you encounter any problems in applying this framework in the course of your work?

b. If yes: do you see any scope for improvement?

8. Do you have any experience or knowledge of alternative regimes (such as those in other countries? 
Criminal offence committed

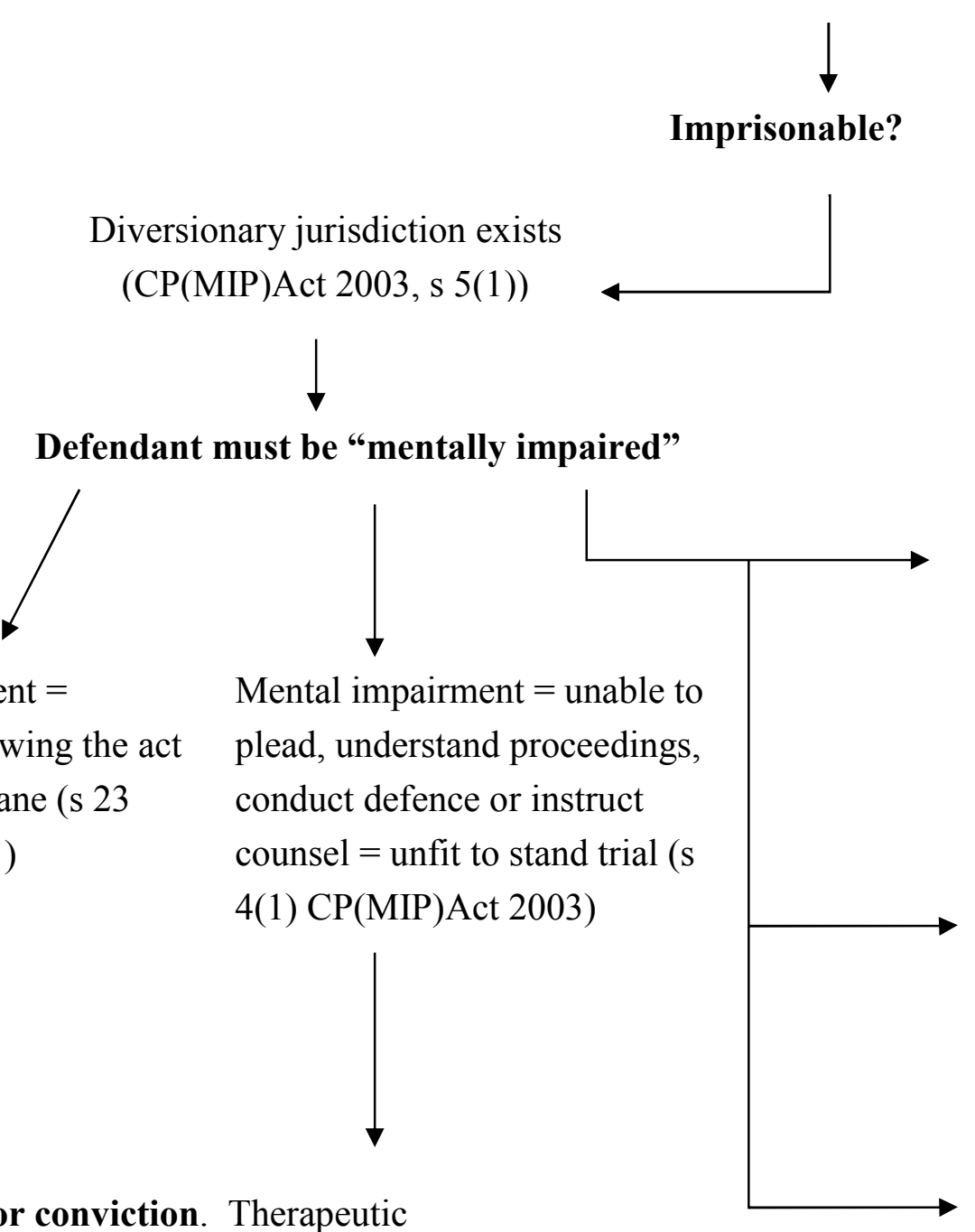

No trial or conviction. Therapeutic
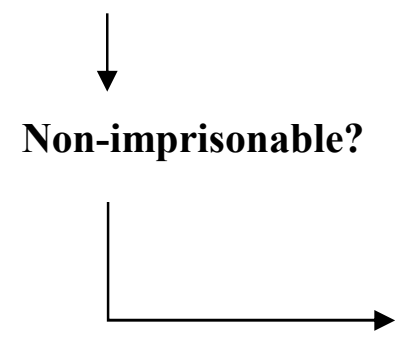

No diversionary process available.

Offending can be used to initiate civil

commitment under $\mathrm{MH}(\mathrm{CAT}) \mathrm{Act} 1992$ (see Ministry of Health $v$ M FC Manukau, FAM2006-092-2802, 21 December 2006).

Mental impairment $=$ "mental

disorder" under s 2(1)

MH(CAT)Act 1992 and

treatment required for offender's

interest or public safety

Conviction and therapeutic

Mental impairment $=$

Mental impairment $=$ unable to

incapable of knowing the act

was wrong $=$ insane (s 23

Crimes Act 1961)

conduct defence or instruct counsel $=$ unfit to stand trial $(\mathrm{s}$

Mental impairment $=$

disposition under ss 34(1)(a)(i) or 34(1)(b)(i) CP(MIP)Act 2003 = treatment in "hospital" under MH(CAT)Act 1992

“intellectual disability" under s 7

Conviction and therapeutic

ID(CCR)Act 2003 and care disposition under ss 34(1)(a)(ii) required for offender's interest or or 34(1)(b)(ii) CP(MIP)Act public safety $2003=$ care in "facility" under ID(CCR)Act 2003

Mental impairment $=$ outside jurisdiction of s $34 \mathrm{CP}(\mathrm{MIP}) \mathrm{Act}=$ conviction and sentence as per dispositions under ss 24 or 25 CP(MIP)Act Sentencing Act 2002 (mitigating factors mav applv)

Treatment in prison $(\mathrm{s} 75$

Corrections Act 2004)

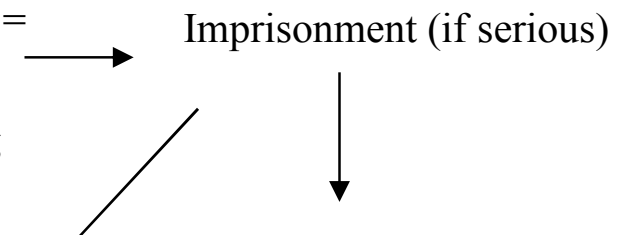

Transfer for treatment (ss 45 or $46 \mathrm{MH}(\mathrm{CAT}) \mathrm{Act}$ 1992) or care (s 45 ID(CCR)Act 2003) 